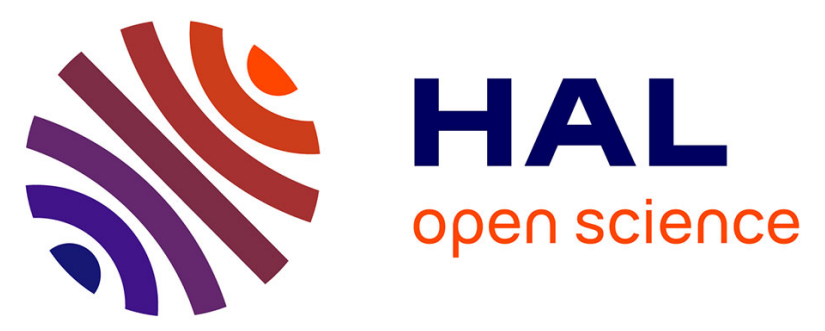

\title{
Dissolution Anisotropy of Pyroxenes: A Surrogate Model for Steady-State Enstatite Dissolution Resulting from Stochastic Simulations of the Hydrolysis Process
}

Arnaud Bouissonnié, Damien Daval, Philippe Ackerer

\section{- To cite this version:}

Arnaud Bouissonnié, Damien Daval, Philippe Ackerer. Dissolution Anisotropy of Pyroxenes: A Surrogate Model for Steady-State Enstatite Dissolution Resulting from Stochastic Simulations of the Hydrolysis Process. Journal of Physical Chemistry C, 2020, 124 (24), pp.13113-13126. 10.1021/acs.jpcc.0c00962 . hal-03010626

\section{HAL Id: hal-03010626 \\ https://hal.science/hal-03010626}

Submitted on 17 Nov 2020

HAL is a multi-disciplinary open access archive for the deposit and dissemination of scientific research documents, whether they are published or not. The documents may come from teaching and research institutions in France or abroad, or from public or private research centers.
L'archive ouverte pluridisciplinaire HAL, est destinée au dépôt et à la diffusion de documents scientifiques de niveau recherche, publiés ou non, émanant des établissements d'enseignement et de recherche français ou étrangers, des laboratoires publics ou privés. 
1 The Dissolution Anisotropy of Pyroxenes: A Surrogate Model for

2

3

4

5

6

7

8

9

10

11

12

13

14

15

16

17

18

19

20

21

22

23

\section{Simulations of the Hydrolysis Process}

Arnaud Bouissonnié ${ }^{1, *}$, Damien Daval ${ }^{1}$, Philippe Ackerer ${ }^{1}$

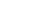

${ }^{1}$ Université de Strasbourg - CNRS / ENGEES - EOST, Laboratoire d'Hydrologie et de

Géochimie de Strasbourg, 1 Rue Blessig, 67084 Strasbourg, France

*corresponding author: arnaud.bouissonnie@etu.unistra.fr (A. Bouissonnié)

Tel: +33 (0)3 688505 47; Fax: +33(0)3 68850402

2




\section{Abstract}

Over the past decades, the field of mineral dissolution kinetics has undergone a spectacular evolution, with an increasingly detailed description of the atomic scale mechanisms of fluidsolid interactions. The development of probabilistic dissolution models has played a prominent role in this evolution, as they allow for bridging the outputs of $a b$ initio calculations to macroscopic observables such as dissolution rates and nanoscale surface features. It is however admitted that these models cannot be easily adapted to simulate natural systems at large space and time scales due to the restricted dimensions and durations that can be simulated numerically. In the present study, we demonstrate that the steady-state outputs of the face-specific stochastic treatment of enstatite dissolution, which was experimentally validated in a previous paper, can be boiled down to a single analytical expression under the form:

$$
r_{b u l k}^{(h k l)}=k P_{M g-O-M g}^{\alpha} P_{M g-O-S i}^{\beta} P_{S i-O-S i}^{\gamma}
$$

where $r_{b u l k}^{(h k l)}$ is the steady-state dissolution rate of a defect-free $(h k l)$ face [ $\AA /$ iter], $P_{M-O-M}$ ' stands for the bond-breaking probability of the M-O-M' bond, and $k, \alpha, \beta$ and $\gamma$ are fitting parameters adjusted following the outputs of the stochastic simulations. When dislocations outcrop at the surface of a given $(h k l)$ face of enstatite, the relation then becomes:

$$
r^{(h k l)}=r_{\text {bulk }}^{(h k l)}+r_{\text {dislocation }}^{(h k l)}\left(P_{M g-O-M g}, P_{M g-O-S i}, P_{S i-O-S i}\right)
$$

where $r_{\text {dislocation }}^{(h k l)}$ stands for the contribution of the dislocations to the overall dissolution rate. The derivation of simple analytical expressions to get steady-state rate data that are similar to those obtained using stochastic dissolution models, may contribute to parametrize efficiently the bond-breaking probability of various atoms for pyroxene solid solutions, and raises the question of the extension of such surrogate expressions to other silicate structures. Finally, the 
48 development of surrogate models such as those reported here represents one of the possible 49 strategies for upscaling dissolution processes from the atomic scale to the micron scale. 


\section{Introduction}

Many complementary approaches have been developed to predict the fate of waterrock interactions, at various space and time scales. Historically, the conceptual framework underpinning the corresponding models has been closely linked to the disciplinary field in which they were developed.

When dealing with the Earth system, the first attempts to develop weathering rate laws for large space $\left(\mathrm{km}^{2}\right)$ and time (Myr) scales were undoubtedly phenomenological, and strongly relied on empirical relations. The pioneering work of Berner and coworkers, aimed at reconstructing the evolution of the $\mathrm{CO}_{2}$ concentration in the atmosphere during the Phanerozoic through the development of the BLAG ${ }^{1}$ and GEOCARB ${ }^{2-4}$ codes, was based on model weathering reactions, whose rates were largely parametrized according to empirical rate-runoff, rate- $\mathrm{pCO}_{2}$ and rate-temperature relations inferred from field measurements. Since the early 90 s, this approach has been gradually superseded by reactive transport models, where the source-terms of the classical reaction-dispersion-advection equation are described following kinetic rate laws derived from dissolution experiments conducted on powdered single-crystals. Although the corresponding rate equations, which relate the dissolution rate to fundamental parameters such as temperature, $\mathrm{pH}$, surface area or solution saturation state, were originally claimed to result from the transition state theory (TST) ${ }^{5-7}$, several studies subsequently questioned the theoretical validity of the extension of TST to silicate dissolution ${ }^{8-9}$, the experimental validation of which being described as nothing more than a fitting exercise with little physical basis by some authors ${ }^{10}$. More generally, a growing number of experimental studies have underlined the limitations of TST-based relations, which fail to accurately relate dissolution rates to solution saturation state ${ }^{11-19}$, and are unable to account for the variability (heterogeneity and anisotropy) of crystal dissolution rates ${ }^{20-28}$. With respect to the relation between dissolution rate and fluid saturation state, the deviation from a TST- 
behavior has often been attributed to the nucleation and opening of etch pits where dislocations outcrop at the mineral's surface ${ }^{11,19,23,29-32}$. Etch pits have been extensively reported for a wide variety of minerals ${ }^{22-23,32-38}$, when the fluid under saturation is large enough and does not exceed a critical value of the Gibbs free energy. The efficiency of these sites to enhance mineral dissolution rate has been showed both experimentally and numerically, and is accounted for by the stepwave model ${ }^{31}$. At the atomic-scale, the opening of etch pits results in an increase of the density of kink and step sites. This process exposes atoms with a lower coordination to the fluid which are, as a result, more rapidly dissolved. More generally, the reactivity of minerals is highly heterogeneous, with hotspots of reactivity such as kinks, steps (and ultimately crystal edges and corners) and can be accurately captured by the "rate spectra" concept ${ }^{20,39}$. Finally, several studies have pointed out that mineral dissolution is anisotropic ${ }^{19}, 22-23,38,40-41$, resulting from the anisotropic distribution of atomic positions in the crystal lattice. These observations have emphasized the need for deeper experimental and theoretical studies of fluid-mineral interactions from the atomic- to the nmscale to unravel the dissolution mechanisms.

Precisely at the other end of the spatiotemporal spectrum, the advent of microscopic and spectroscopic techniques of characterization of the fluid-mineral interface offered new avenues to understand mineral reactivity ${ }^{26,}{ }^{42-53}$. Studies dedicated to the molecular-scale description of the silicate dissolution process following ab initio quantum mechanical calculations and molecular dynamics (MD) models emerged some 20 years ago ${ }^{54-59}$. These studies provided essential theoretical insights into the dissolution process. Admittedly, the corresponding studies have been of limited direct interest (and were not intended) to model chemical weathering in natural settings, due to the restricted durations and dimensions of the system that can be simulated numerically. 
A first intermediate step in the upscaling process of dissolution reaction rates has been successfully reached with the emergence of stochastic models of silicate and carbonate dissolution $^{25,28,36,48,53,57,60-69}$, whose parametrization may strongly rely on the results of $a b$ initio calculations mentioned above, with considerable simplifications of the reaction details. Such an approach dramatically increased the size of the studied systems from clusters of a few atoms to nanocrystals of several tens of millions of atoms, simulating time scales of up to several weeks ${ }^{41,70}$. However, implementing such models into reactive transport codes is not an easy task since they usually do not provide the rate laws that are required by these codes to predict the rates of water-rock interactions at large space and time scales ${ }^{71-72}$. Promising strategies combining Monte Carlo simulations and Voronoi methods have been recently developed to circumvent this issue ${ }^{39,73}$, offering the perspective to reach the next step in the upscaling process, i.e., the continuum scale, where reactive transport can be applied. Such recent breakthroughs emphasize the crucial importance of maintaining efforts to investigate into more details the various theoretical and empirical emerging relations of stochastic dissolution models, which represents one of the goals of the present paper.

In a previous study ${ }^{41}$, we developed a probabilistic model of enstatite dissolution which successfully reproduced the measured anisotropy of enstatite dissolution rates and associated surface features. In the present study, hundreds of simulations were conducted with this model by varying the bond-breaking probabilities of the crystal-to explore the analytical relation that may link together the detachment of individual atoms from the enstatite surface to the overall face-specific dissolution rates. This work was in part motivated by the fact that mineral dissolution kinetics is often treated by mixing macroscopic parameters with microscopic ones, resulting in rate laws for which the theoretical basis remains questionable (see discussion in e.g. ${ }^{9}$ ). Here we illustrate how overall rate constants may be derived from atomic-scale parameters, considering especially the bond-breaking probability of hydrolysis 
processes. In particular, we show that, at steady-state conditions, an analytical relation can be derived to express the overall dissolution rate constant, whose parameters can be adjusted following the outputs of numerical simulations performed at the atomic scale. We then show that the resulting analytical relation can be used to predict the steady-state enstatite facespecific dissolution rates over a wide range of bond-breaking probabilities. This relation is then further extended from defect-free surfaces to defective surfaces impacted by screw dislocations. Finally, we discuss the implications of such surrogate expressions, both from the perspective of the mechanisms of pyroxene dissolution and for the upscaling of silicate dissolution rates.

\section{Methods}

\subsection{Model description and algorithms}

A complete description of the model is given in Bouissonnié et al. ${ }^{41}$. In short, the positions of $\mathrm{Mg}$, Si and $\mathrm{O}$ atoms provided by Hugh-Jones and Angel ${ }^{74}$ are used to create the enstatite cell thanks to the symmetry elements of the $\mathrm{Pbca}$ space group. $\mathrm{Mg}$ and $\mathrm{Si}$ atoms are then linked to the 6 and 4 nearest $O$ atoms respectively. Since probabilistic dissolution models generally consider the bond-breaking probabilities of $\mathrm{M}-\mathrm{O}-\mathrm{M}$ ' bonds ${ }^{30,36,69}$, each $\mathrm{Mg}$ and $\mathrm{Si}$ atom is connected to its first coordination sphere ${ }^{36}$.

Usually, the probability attributed with one event (i.e. the bond-breaking probability) is written as follows ${ }^{30}$ :

$$
P=e^{\frac{-E_{a}}{k_{B} T}}
$$

where $P$ stands for the bond-breaking probability, $E_{a}$ for the activation energy of the bond hydrolysis $(\mathrm{J}), k_{B}$ for the Boltzmann constant $(\mathrm{J} / \mathrm{K})$ and $T$ for the temperature $(\mathrm{K})$. In the present study, the most likely bond-breaking probability (i.e., the bond hydrolysis associated 
to with the lowest activation energy, $\mathrm{Mg}-\mathrm{O}-\mathrm{Mg}$ ) was arbitrarily set to 0.99 and the two other probabilities were scaled according to the differences between their corresponding activation energies following:

$$
\frac{P_{A}}{P_{B}}=e^{-\frac{\left(E_{a}^{A}-E_{a}^{B}\right)}{k_{B} T}}
$$

where $\mathrm{A}$ and $\mathrm{B}$ represent two different bonds.

In agreement with previous studies ${ }^{48,61-66}$, an "all-or-none" approach has been used. This approach considers the hydrolysis of atoms instead of individual bonds. In other words, for a given simulated step, an atom is released only when all the remaining bonds that connect the atom to the surface of the crystal are broken simultaneously. Otherwise, the corresponding atom remains connected to the surface. The probability of an atom $\mathrm{M}$ to be released in the fluid depends on the number and type of atomic bonds present in its first coordination sphere. In the case of the enstatite, this probability can be written as follows:

$$
P_{M}=e^{-n \frac{E_{M-O-M g}}{k_{B} T}} e^{-m \frac{E_{M-O-S i}}{k_{B} T}}=P_{M-O-M g}^{n} P_{M-O-S i}^{m}
$$

where $n$ and $m$ stand for the number of bonds that the considered atom shares with $\mathrm{Mg}$ and $\mathrm{Si}$ atoms respectively.

The dissolution algorithm was described in details in Bouissonnié et al. ${ }^{41}$ and is schematically represented in Fig. 1. Such algorithms have previously proven successful to simulate the dissolution of silicate materials (e.g. ${ }^{41,48,61}$ ). In short, a random number $Z$ uniformly distributed between 0 and 1 is drawn for each atom at the surface defined by an incomplete coordination sphere (i.e. an atom at the crystal surface). If $Z<P_{M}$, all atomic bounds are broken and the atom is considered as dissolved (removed from the surface); if not, the atom stays at the surface. The first coordination spheres of the remaining atoms are then updated if necessary (i.e., when a removed atom was belonging to the coordination spheres of one of the neighboring remaining atoms). Because coordination spheres are modified, the 
probability of dissolution $P_{M}$ of the corresponding atoms increases. In such kinds of algorithms, each iteration step corresponds to a given simulated duration, and the time-step is therefore constant for all simulations. The proportionality factor to convert the number of iterations into time is not known a priori, and can be determined by comparing the outputs of a simulation with experimental data (see ${ }^{41}$ for details). This aspect contrasts with kinetic Monte Carlo algorithms based on a "divide and conquer" approach 36,63 , which use an adaptive time step that varies at each iteration as a function of the random number that is drawn, corresponding to a specific surface site that is dissolved during the iteration. The main strengths of the "divide and conquer" approach are that they allow for a direct link between time and the number of iterations, while precluding the existence of "dead" iterations, reducing accordingly the computing time required to simulate a given process. Conversely, "dead" iterations may sometimes occur over the course of the algorithm that we used (essentially, at the beginning of the simulations), but as opposed to the "divide and conquer" approach, it allows for simultaneous events to occur over a given iteration (and time step). Although both methods should ultimately provide identical results (see theoretical derivation in ${ }^{75}$ ), to the best of our knowledge, a comparison between both types of algorithms has never been proposed for mineral dissolution, and is out of the scope of the present study.

The impact of dislocation density has also been studied by running additional simulations for the (100) face. Dislocations were introduced as lines running parallel to the [100] axis, in agreement with previous observations ${ }^{76}$. To simulate the faster dissolution at dislocation sites (placed at the center of the reactive surface), the bond-breaking probabilities associated to with the atoms belonging to the dislocation line were set to 1 following Kurganskaya and LuttgeKurganskaya and Luttge ${ }^{36}$. 


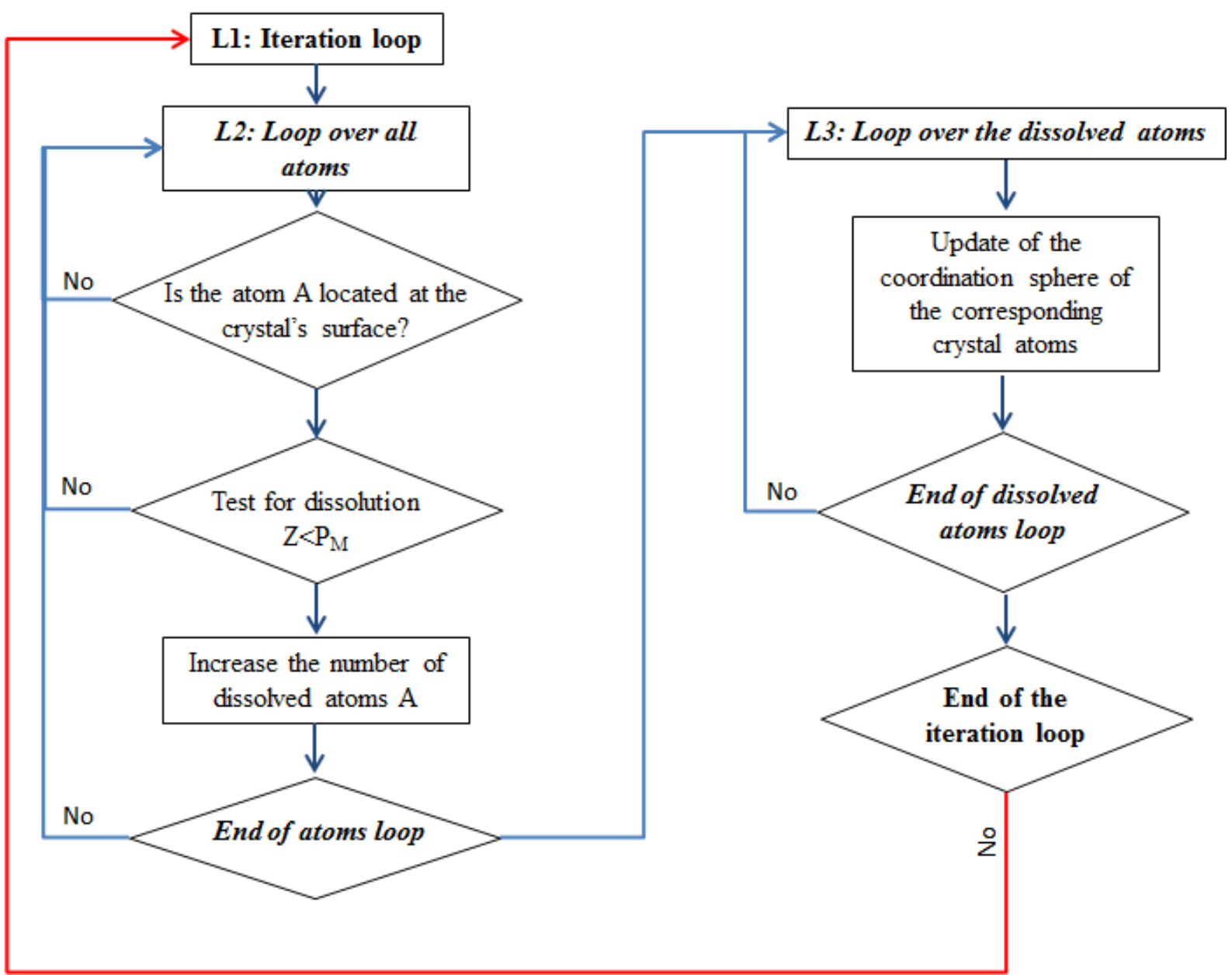

Figure 1 Scheme of the numerical algorithm of the probabilistic model.

Finally, the boundary conditions (BC) were set as follows: atoms that are part of the sides of the simulated volume cannot be dissolved. Since it can induce a dependence of the dissolution rate on the dimensions of the simulated surface, we verified that the simulated surface area was large enough to avoid any impact of the $\mathrm{BC}$ on the dissolution rate. 

stored at each step (iteration). In this study, the dissolution rate calculation is based on the release of $\mathrm{Si}$ atoms (equivalent to the one based on $\mathrm{Mg}$ atoms departure and mean surface height at steady-state conditions ${ }^{41}$ ):

$$
r^{(h k l)}=\frac{V_{\text {cell }}}{i \text { ter } \times N_{\text {Si,cell }} \times S} \sum_{i=1}^{i t e r} N_{S i, i}
$$

206

207

where $r^{(h k l)}$ stands for the dissolution rate $(\AA /$ it) of a given face (here, either $(100),(010)$ or (001)), $N_{S i, i}$ for the number of Si atoms released at each iteration $i, N_{S i, c e l l}$ for the number of $\mathrm{Si}$ atoms in enstatite cell (16), iter for the total number of iterations, and $S$ for the geometric surface area of the crystal face $\left(\AA^{2}\right)$. The second output of the model is related to the chemical environment of the atoms when they are released from the surface. In particular, knowledge of the first coordination sphere of each atom that has been dissolved allows for the determination of the number of $\mathrm{Mg}$ and $\mathrm{Si}$ atoms that were connected to the released $\mathrm{M}$ atoms. As opposed to other similar numerical studies (e.g. ${ }^{77-78}$ ), our study was not aimed to capture the intrinsic heterogeneous distribution of reaction rates at the simulated crystal surface. Instead, our primary goal was to provide an analytical expression for the overall facespecific steady state dissolution rate as a function of bond-breaking probabilities, which has to be achieved at the scale of a given face, echoing the face-specific dissolution rates frequently reported from dissolution experiments (see ${ }^{39,79}$ for an overview).

\section{Results}

\subsection{Dissolution rate evolution as a function of bond-breaking probabilities}



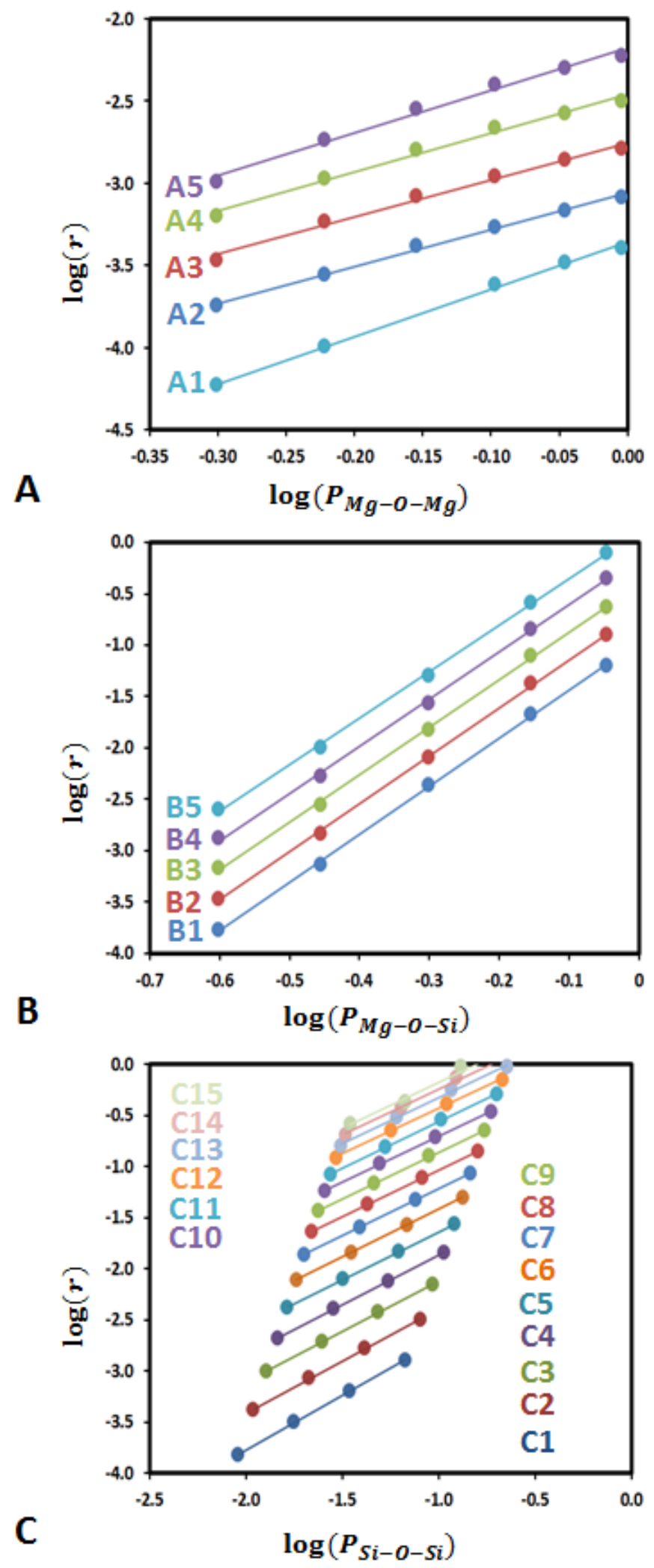

Fig.2. Results of the different simulations for the (100) face. Each graph represents the evolution of the steadystate dissolution rate as a function of the logarithm of: (A) $\mathrm{P}_{\mathrm{Mg}-\mathrm{O}-\mathrm{Mg}}$, (B) $\mathrm{P}_{\mathrm{Mg}-\mathrm{O}-\mathrm{Si}}$ and (C) $\mathrm{P}_{\mathrm{Si}-\mathrm{O}-\mathrm{Si}}$. Each color represents a different $\Delta \mathrm{Ea}$ between the two other probabilities which remains fixed. Slopes and intercepts are listed in Table 1. Legends correspond to the code indicated for each group of simulations. These codes are used in Table 1 to indicate which simulation corresponds to which groups of data. 


\begin{tabular}{|c|c|c|c|c|c|c|c|c|c|c|}
\hline & $P_{M g-O-M g}$ & $P_{M g-O-S i}$ & $P_{S i-O-S i}$ & $\begin{array}{c}\Delta \mathrm{E} \\
(\mathrm{Mg}-\mathrm{O}-\mathrm{Mg}-\mathrm{Mg}-\mathrm{O}-\mathrm{Si}) \\
(\mathrm{kJ} / \mathrm{mol})\end{array}$ & $\begin{array}{c}\Delta \mathrm{E} \\
(\mathrm{Mg}-\mathrm{O}-\mathrm{Si}-\mathrm{Si}-\mathrm{O}-\mathrm{Si}) \\
(\mathrm{kJ} / \mathrm{mol})\end{array}$ & $\begin{array}{c}\Delta \mathrm{E} \\
(\mathrm{Mg}-\mathrm{O}-\mathrm{Mg}-\mathrm{Si}-\mathrm{O}-\mathrm{Si}) \\
(\mathrm{kJ} / \mathrm{mol})\end{array}$ & $\mathrm{a}$ & $\mathrm{b}$ & $\mathrm{R}^{2}$ & $\begin{array}{l}\text { Fig } 2 \\
\text { code }\end{array}$ \\
\hline \multirow{14}{*}{ (100) } & $0.99-0.50$ & 0.30 & 0.01 & - & 10.0 & - & 2.87 & -3.36 & 1.00 & A1 \\
\hline & $0.99-0.60$ & 0.30 & 0.02 & - & 8.0 & - & 2.23 & -3.06 & 1.00 & $\mathrm{~A} 2$ \\
\hline & $0.99-0.70$ & 0.30 & 0.04 & - & 6.0 & - & 2.26 & -2.75 & 0.99 & A3 \\
\hline & $0.99-0.80$ & 0.30 & 0.08 & - & 4.0 & - & 2.37 & -2.46 & 0.99 & A4 \\
\hline & $0.99-0.90$ & 0.30 & 0.15 & - & 2.0 & - & 2.59 & -2.18 & 0.99 & A5 \\
\hline & 0.99 & $0.90-0.25$ & 0.01 & - & - & 14.0 & 4.68 & -0.97 & 1.00 & $\mathrm{~B} 1$ \\
\hline & 0.99 & $0.90-0.26$ & 0.02 & - & - & 12.0 & 4.67 & -0.68 & 1.00 & $\mathrm{~B} 2$ \\
\hline & 0.99 & $0.90-0.27$ & 0.04 & - & - & 10.0 & 4.62 & -0.41 & 1.00 & B3 \\
\hline & 0.99 & $0.90-0.28$ & 0.07 & - & - & 8.0 & 4.59 & -0.15 & 1.00 & B4 \\
\hline & 0.99 & $0.90-0.29$ & 0.14 & - & - & 6.0 & 4.53 & 0.10 & 1.00 & B5 \\
\hline & 0.99 & 0.25 & $0.0665-0.0091$ & 4.2 & - & - & 1.06 & -1.64 & 1.00 & $\mathrm{C} 1$ \\
\hline & 0.99 & 0.30 & $0.0798-0.0109$ & 3.6 & - & - & 1.02 & -1.37 & 1.00 & $\mathrm{C} 2$ \\
\hline & 0.99 & 0.35 & $0.0930-0.0128$ & 3.1 & - & - & 0.98 & -1.14 & 1.00 & $\mathrm{C} 3$ \\
\hline & 0.99 & 0.40 & $0.1063-0.0146$ & 2.7 & - & - & 0.97 & -0.90 & 1.00 & $\mathrm{C} 4$ \\
\hline
\end{tabular}




\begin{tabular}{|c|c|c|c|c|c|c|c|c|c|}
\hline 0.99 & 0.45 & $0.1196-0.0164$ & 2.4 & - & - & 0.94 & -0.70 & 1.00 & $\mathrm{C} 5$ \\
\hline 0.99 & 0.50 & $0.1329-0.0182$ & 2.1 & - & - & 0.93 & -0.49 & 1.00 & C6 \\
\hline 0.99 & 0.55 & $0.1462-0.2000$ & 1.8 & - & - & 0.92 & -0.29 & 1.00 & $\mathrm{C} 7$ \\
\hline 0.99 & 0.60 & $0.1595-0.0219$ & 1.5 & - & - & 0.92 & -0.12 & 1.00 & $\mathrm{C} 8$ \\
\hline 0.99 & 0.65 & $0.1728-0.0237$ & 1.3 & - & - & 0.91 & 0.05 & 1.00 & C9 \\
\hline 0.99 & 0.70 & $0.1861-0.0255$ & 1.0 & - & - & 0.90 & 0.20 & 1.00 & $\mathrm{C} 10$ \\
\hline 0.99 & 0.75 & $0.1994-0.0273$ & 8.4 & - & - & 0.90 & 0.34 & 1.00 & $\mathrm{C} 11$ \\
\hline 0.99 & 0.80 & $0.2127-0.0292$ & 6.4 & - & - & 0.89 & 0.45 & 1.00 & $\mathrm{C} 12$ \\
\hline 0.99 & 0.85 & $0.2260-0.0310$ & 4.6 & - & - & 0.90 & 0.57 & 1.00 & $\mathrm{C} 13$ \\
\hline 0.99 & 0.90 & $0.2393-0.0328$ & 2.9 & - & - & 0.90 & 0.66 & 1.00 & $\mathrm{C} 14$ \\
\hline 0.99 & 0.95 & $0.2526-0.0346$ & 1.2 & - & - & 0.89 & 0.72 & 0.99 & $\mathrm{C} 15$ \\
\hline
\end{tabular}




\begin{tabular}{|c|c|c|c|c|c|c|c|c|c|}
\hline & $P_{M g-O-M g}$ & $P_{M g-O-S i}$ & $P_{S i-O-S i}$ & $\begin{array}{l}\Delta \mathrm{E} \\
(\mathrm{Mg}-\mathrm{O}-\mathrm{Mg}-\mathrm{Mg}-\mathrm{O}-\mathrm{Si}) \\
(\mathrm{kJ} / \mathrm{mol})\end{array}$ & $\begin{array}{l}\Delta \mathrm{E} \\
(\mathrm{Mg}-\mathrm{O}-\mathrm{Si}-\mathrm{Si}-\mathrm{O}-\mathrm{Si}) \\
(\mathrm{kJ} / \mathrm{mol})\end{array}$ & $\begin{array}{l}\Delta \mathrm{E} \\
(\mathrm{Mg}-\mathrm{O}-\mathrm{Mg}-\mathrm{Si}-\mathrm{O}-\mathrm{Si}) \\
(\mathrm{kJ} / \mathrm{mol})\end{array}$ & $\mathrm{a}$ & $\mathrm{b}$ & $\mathrm{R}^{2}$ \\
\hline & $0.99-0.50$ & 0.30 & 0.01 & - & 10.0 & - & 2.18 & -3.08 & 1.00 \\
\hline & $0.99-0.60$ & 0.30 & 0.02 & - & 8.0 & - & 2.24 & -2.83 & 1.00 \\
\hline & $0.99-0.70$ & 0.30 & 0.04 & - & 6.0 & - & 2.24 & -2.60 & 1.00 \\
\hline & $0.99-0.90$ & 0.30 & 0.15 & - & 2.0 & - & 2.21 & -2.18 & 1.00 \\
\hline & 0.99 & $0.90-0.25$ & 0.01 & - & - & 14.0 & 4.48 & -0.78 & 1.00 \\
\hline \multirow[t]{5}{*}{ (010) } & 0.99 & $0.90-0.26$ & 0.02 & - & - & 12.0 & 4.48 & -0.54 & 1.00 \\
\hline & 0.99 & $0.90-0.29$ & 0.14 & - & - & 6.0 & 4.79 & 0.29 & 1.00 \\
\hline & 0.99 & 0.25 & $0.0665-0.0091$ & 4.2 & - & - & 0.75 & -1.92 & 1.00 \\
\hline & 0.99 & 0.30 & $0.0798-0.0109$ & 3.6 & - & - & 0.82 & -1.48 & 1.00 \\
\hline & 0.99 & 0.35 & $0.0930-0.0128$ & 3.1 & - & - & 0.75 & -1.23 & 1.00 \\
\hline
\end{tabular}




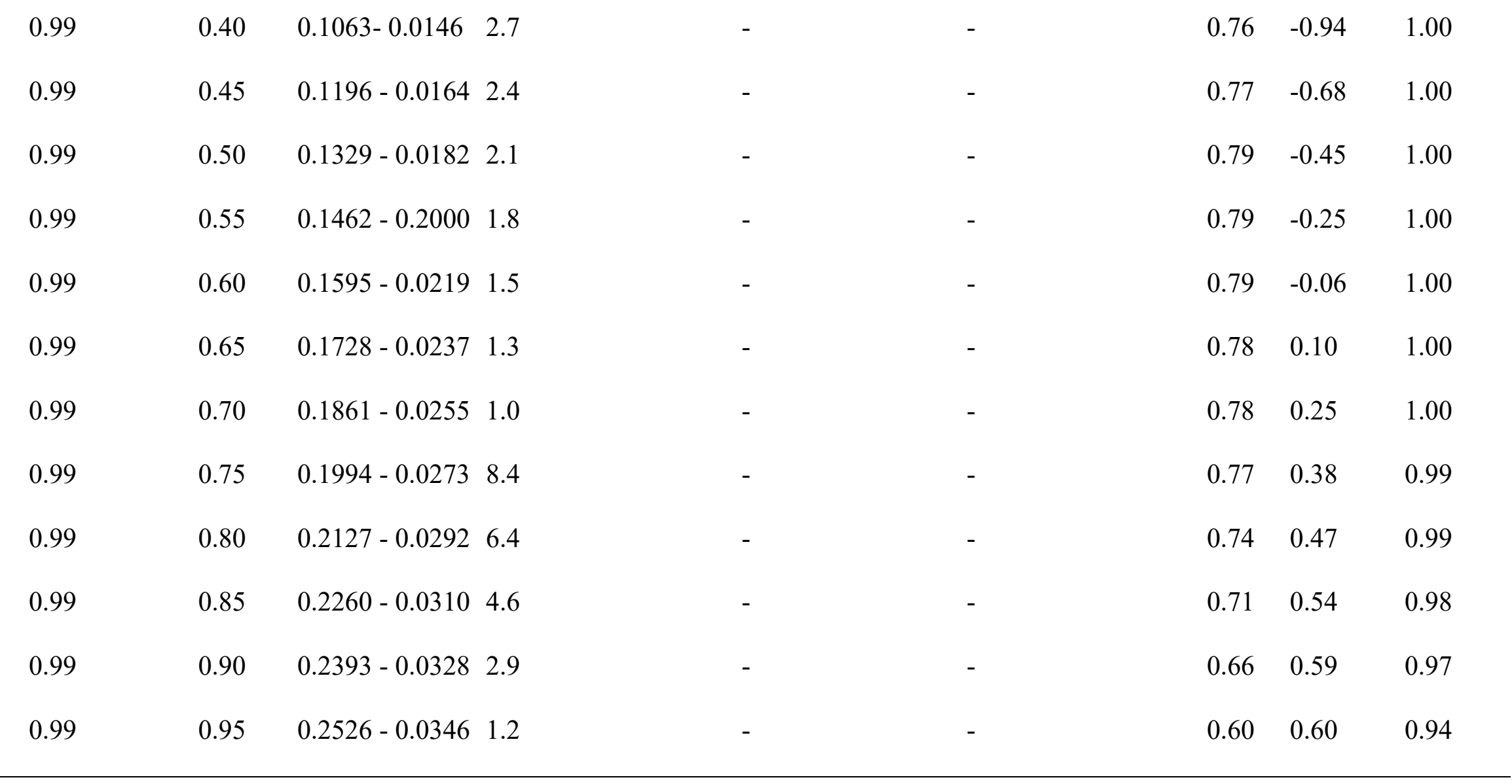




\begin{tabular}{|c|c|c|c|c|c|c|c|c|c|}
\hline & $P_{M g-O-M g}$ & $P_{M g-O-S i}$ & $P_{S i-O-S i}$ & $\begin{array}{l}\Delta \mathrm{E} \\
(\mathrm{Mg}-\mathrm{O}-\mathrm{Mg}-\mathrm{Mg}-\mathrm{O}-\mathrm{Si}) \\
(\mathrm{kJ} / \mathrm{mol})\end{array}$ & $\begin{array}{l}\Delta \mathrm{E} \\
(\mathrm{Mg}-\mathrm{O}-\mathrm{Si}-\mathrm{Si}-\mathrm{O}-\mathrm{Si}) \\
(\mathrm{kJ} / \mathrm{mol})\end{array}$ & $\begin{array}{l}\Delta \mathrm{E} \\
(\mathrm{Mg}-\mathrm{O}-\mathrm{Mg}-\mathrm{Si}-\mathrm{O}-\mathrm{Si}) \\
(\mathrm{kJ} / \mathrm{mol})\end{array}$ & $\mathrm{a}$ & $\mathrm{b}$ & $\mathrm{R}^{2}$ \\
\hline & $0.99-0.50$ & 0.30 & 0.01 & - & 10.0 & - & 7.46 & -1.72 & 1.00 \\
\hline & $0.99-0.60$ & 0.30 & 0.02 & - & 8.0 & - & 6.77 & -1.77 & 1.00 \\
\hline & $0.99-0.70$ & 0.30 & 0.04 & - & 6.0 & - & 6.64 & -1.73 & 0.99 \\
\hline & $0.99-0.90$ & 0.30 & 0.15 & - & 2.0 & - & 5.05 & -1.73 & 0.96 \\
\hline & 0.99 & $0.90-0.25$ & 0.01 & - & - & 14.0 & 4.09 & 0.39 & 1.00 \\
\hline \multirow[t]{5}{*}{$(001)$} & 0.99 & $0.90-0.26$ & 0.02 & - & - & 12.0 & 4.20 & 0.46 & 1.00 \\
\hline & 0.99 & $0.90-0.29$ & 0.14 & - & - & 6.0 & 4.23 & 0.51 & 1.00 \\
\hline & 0.99 & 0.25 & $0.0665-0.0091$ & 4.2 & - & - & 0.17 & -1.81 & 0.99 \\
\hline & 0.99 & 0.30 & $0.0798-0.0109$ & 3.6 & - & - & 0.15 & -1.52 & 0.97 \\
\hline & 0.99 & 0.35 & $0.0930-0.0128$ & 3.1 & - & - & 0.13 & -1.27 & 0.98 \\
\hline
\end{tabular}




\begin{tabular}{|c|c|c|c|c|c|c|c|c|}
\hline 0.99 & 0.40 & $0.1063-0.0146$ & 2.7 & - & - & 0.12 & -1.04 & 0.99 \\
\hline 0.99 & 0.45 & $0.1196-0.0164$ & 2.4 & - & - & 0.15 & -0.80 & 0.99 \\
\hline 0.99 & 0.50 & $0.1329-0.0182$ & 2.1 & - & - & 0.12 & -0.63 & 0.99 \\
\hline 0.99 & 0.55 & $0.1462-0.2000$ & 1.8 & - & - & 0.12 & -0.45 & 0.99 \\
\hline 0.99 & 0.60 & $0.1595-0.0219$ & 1.5 & - & - & 0.11 & -0.30 & 0.99 \\
\hline 0.99 & 0.65 & $0.1728-0.0237$ & 1.3 & - & - & 0.12 & -0.14 & 1.00 \\
\hline 0.99 & 0.70 & $0.1861-0.0255$ & 1.0 & - & - & 0.14 & 0.02 & 1.00 \\
\hline 0.99 & 0.75 & $0.1994-0.0273$ & 8.4 & - & - & 0.14 & 0.14 & 0.99 \\
\hline 0.99 & 0.80 & $0.2127-0.0292$ & 6.4 & - & - & 0.14 & 0.26 & 0.99 \\
\hline 0.99 & 0.85 & $0.2260-0.0310$ & 4.6 & - & - & 0.14 & 0.35 & 0.98 \\
\hline 0.99 & 0.90 & $0.2393-0.0328$ & 2.9 & - & - & 0.15 & 0.44 & 0.98 \\
\hline 0.99 & 0.95 & $0.2526-0.0346$ & 1.2 & - & - & 0.16 & 0.51 & 0.95 \\
\hline
\end{tabular}

Table 1. Different $\Delta \mathbf{E}_{\mathbf{a}}$ values used in this study (the "-" symbol indicates that $\Delta \mathbf{E}_{\mathbf{a}}$ varies). The slope (a), intercept (b) and correlation coefficient ( $\left.\mathrm{R}^{2}\right)$ of the linear regression

of $\log (\mathbf{r})=\mathbf{f}(\log (\mathbf{P}))$ are given in the last three columns (see text for details). When $\mathrm{P}_{\mathrm{Mg}-\mathrm{O}-\mathrm{Mg}}$ was left constant, its value was set to 0.99. This value allows for minimizing the simulation time required while having the possibility to associate a corresponding physical $\Delta E_{a}$ value. When the relation between dissolution rate and $\mathrm{P}_{\mathrm{Mg}-\mathrm{O}-\mathrm{Mg}}$ was studied,

$\mathrm{P}_{\mathrm{Mg}-\mathrm{O}-\mathrm{Si}}$ was arbitrarily set to 0.3. Finally, the chosen probabilities were constrained by $\mathrm{P}_{\mathrm{Mg}-\mathrm{O}-\mathrm{Mg}}>\mathrm{P}_{\mathrm{Mg}-\mathrm{O}-\mathrm{Si}}>\mathrm{P}_{\mathrm{Si}-\mathrm{O}-\mathrm{Si}}$. 
225 of activation energies. Over these 115 simulations, 30 were dedicated to unravelling the

226 dependence of the dissolution rate evolution on $P_{M g-O-M g}, 25$ on $P_{M g-O-S i}$, and 60 on $P_{S i-O-S i}$.

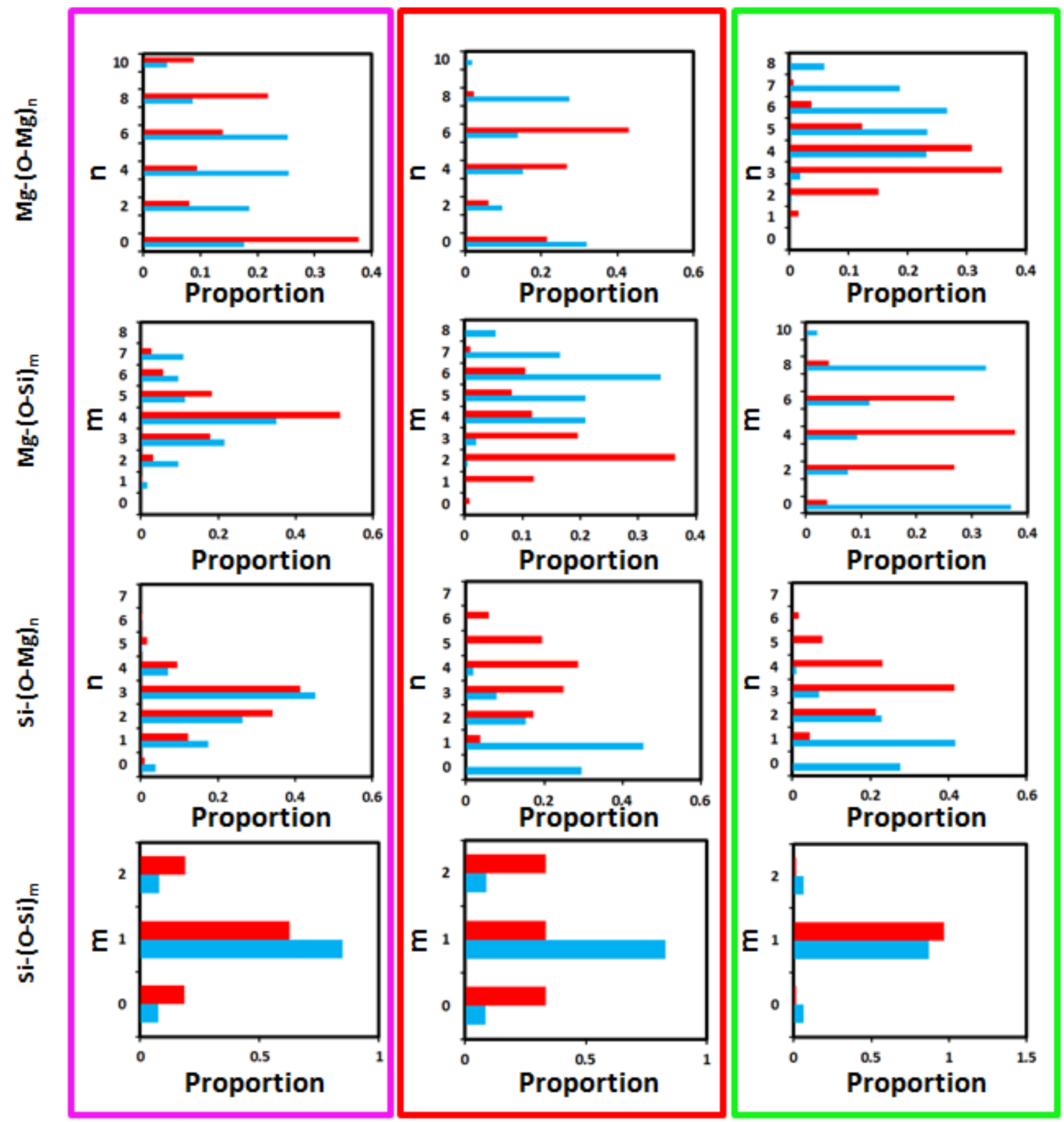

Fig.3. Distribution of the different coordination spheres of an atom right before its dissolution. The first two lines depict Mg atoms, and the following two lines, $\mathrm{Si}$. The proportion is defined by the number of atoms at the surface having $m$ or $n$ bounds divided by the total number of atoms, so that the sum of all modes is 1 . Blue and red bars correspond to a set of low $\left(\mathrm{P}_{\mathrm{Mg}-\mathrm{O}-\mathrm{Mg}}=0.5, \mathrm{P}_{\mathrm{Mg}-\mathrm{O}-\mathrm{Si}}=0.3\right.$ and $\left.\mathrm{P}_{\mathrm{Si}-\mathrm{O}-\mathrm{Si}}=0.0109\right)$ and high $\left(\mathrm{P}_{\mathrm{Mg}-\mathrm{O}-\mathrm{Mg}}=0.99\right.$, $\mathrm{P}_{\mathrm{Mg}-\mathrm{O}-\mathrm{Si}}=0.3$ and $\left.\mathrm{P}_{\mathrm{Si}-\mathrm{O}-\mathrm{Si}}=0.1547\right)$ probability values, respectively. Magenta, red and green rectangle stand for the simulations on (100), (010) and (001) faces respectively. 
As an illustration, the treatment of the outputs of the simulation conducted with the (100) face is depicted in Fig. 2. As expected, the simulations with the lowest probabilities correspond to those resulting in the lowest steady-state dissolution rates. The different datasets of probabilities (one set corresponds to one value of $\mathrm{P}_{\mathrm{Mg}-\mathrm{O}-\mathrm{Mg},} \mathrm{PMg}_{\mathrm{Mg}-\mathrm{O} S \mathrm{Si}}$ and $\mathrm{PSi}_{\mathrm{Si}-\mathrm{O}-\mathrm{Si}}$ as the master variable, all else being constant) have been sorted into different groups according to their fixed $\Delta E a$ value. A total of 25 groups per face were analyzed ( 5 groups of 6 datasets, 5 groups of 5 datasets and 15 groups of 4 datasets for the $r=f\left(P_{M g-O-M g}\right), r=f\left(P_{M g-O-S i}\right)$ and $r=f\left(P_{S i-O-S i}\right)$ cases respectively). These different groups and the full dataset are listed in the Table 1.

A linear relationship between the logarithm of the dissolution rate and the logarithm of the bond-breaking probabilities can be observed for the different simulations (see Fig. 2). This linear model matches results from numerical simulations quite satisfactorily. Moreover, the slope remains constant when changing the activation energy for the hydrolysis of one bond, whatever the difference in the activation energy of the two other bonds (i.e. the slopes are the same for the results shown in each Fig. $2 \mathrm{~A}, 2 \mathrm{~B}$ and $2 \mathrm{C}$ ). Slopes, intercepts and $\mathrm{R}^{2}$ of these linear regressions are listed in Table. 1.

\subsection{Mean first coordination sphere of released atoms}

The attainment of a mean surface configuration when steady-state dissolution rates are reached represents a common trait of all simulations. The corresponding mean first coordination spheres of the $\mathrm{M}$ atoms at the iteration step of their detachment from the surface are depicted in Fig. 3. The coordination spheres will be referred as $\mathrm{M}-(\mathrm{O}-\mathrm{Mg})_{n}$ or $\mathrm{M}-(\mathrm{O}-\mathrm{Si})_{\mathrm{m}}$ in the following ( $n$ and $m$ standing for the number of $\mathrm{Mg}$ and $\mathrm{Si}$ neighbors, respectively). Whereas the coordination of $\mathrm{Si}-(\mathrm{O}-\mathrm{Si})_{\mathrm{m}}$ is dominated by a single mode for which $m=1$, others are more dispersed around one or more principal modes. Regarding $\mathrm{Mg}-(\mathrm{O}-\mathrm{Mg})_{n}, n$ is 
always an even number, regardless of the set of probabilities, consistent with the structure of enstatite. The value of the principal modes of $\mathrm{Mg}-(\mathrm{O}-\mathrm{Mg})_{n}, \mathrm{Mg}-(\mathrm{O}-\mathrm{Si})_{\mathrm{m}}$, and $\mathrm{Si}-(\mathrm{O}-\mathrm{Mg})_{\mathrm{m}}$ depends on the probability and differs from one face to another, as illustrated in Fig. 3, where the blue and red bars corresponds to two distinct sets of probabilities ([P $\mathrm{Pg}-\mathrm{O}-\mathrm{Mg}=0.99, \mathrm{P} \mathrm{Mg}-\mathrm{O}-$ $\left.\mathrm{Si}=0.3, \mathrm{P}_{\mathrm{Si}-\mathrm{O}-\mathrm{Si}}=0.0109\right]$ and $\left[\mathrm{P}_{\mathrm{Mg}-\mathrm{O}-\mathrm{Mg}}=0.7, \mathrm{P}_{\mathrm{Mg}-\mathrm{O}-\mathrm{Si}}=0.3\right.$ and $\left.\left.\mathrm{P}_{\mathrm{Si}-\mathrm{O}-\mathrm{Si}}=0.1547\right]\right)$ selected

257 from the slowest and fastest range of dissolution rates respectively. However, these distributions also reveal that the mean coordination spheres remain constant, regardless of the \pm 0.02 and $1.002 \pm 0.002$ for $\mathrm{Mg}-\mathrm{O}-\mathrm{Mg} ; \mathrm{Mg}-\mathrm{O}-\mathrm{Si}+\mathrm{Mg}-\mathrm{O}-\mathrm{Si}$ and $\mathrm{Si}-\mathrm{O}-\mathrm{Si}$ bonds, respectively).

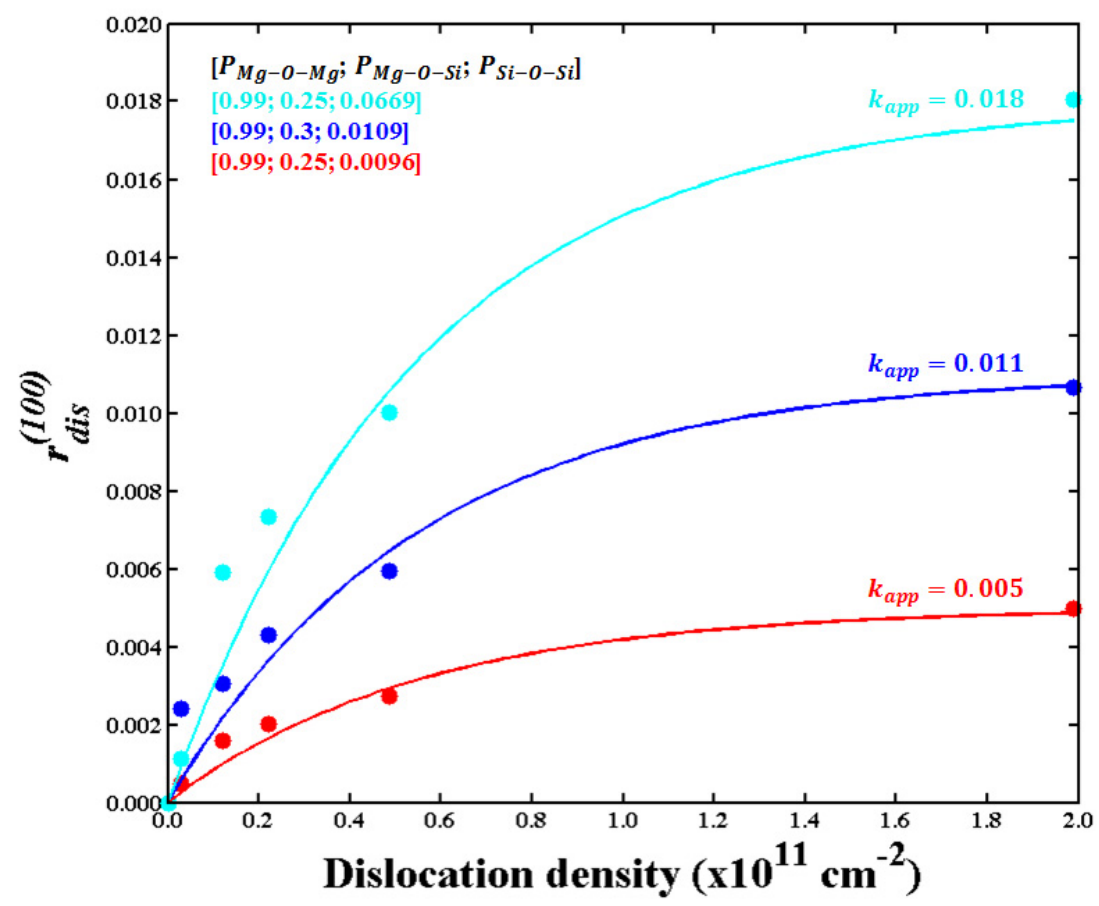

Fig 4. Contribution of dissolution rate specific to dislocations $\left(\boldsymbol{r}_{\text {dislocation }}^{(\mathbf{1 0 0})}\right)$ to the total dissolution rate $\left(\boldsymbol{r}_{i}^{(\mathbf{1 0 0})}\right)$ as a function of the dislocation density. The filled circles represent the results of the different simulations and lines, the application of Eq. 16 using the parameters that allow for the best fit of all the simulations. Colors represent different $\left[P_{M g-O-M g} ; P_{M g-O-S i} ; P_{S i-O-S i}\right]$ input probabilities: $[0.99 ; 0.25 ; 0.0669],[0.99 ; 0.3 ; 0.0109]$ and [0.99; $0.25 ; 0.0096]$ for the cyan, blue and red lines respectively. Values of $k_{\text {app }}$ are $0.018,0.011$ and 0.005 for the cyan, blue and red lines respectively. 


\subsection{Dislocation density}

The results of simulations conducted with dislocations are reported in Fig. 4. The dislocation density has been investigated by varying the surface area (i.e., all simulations were conducted using a single dislocation line, while varying the simulated surface area). Simulations containing dislocations have been conducted on the (100) face. The presented result show the relation between the dissolution rate and the dislocation density after subtraction of the "bulk" contribution to the overall dissolution rate (i.e., $r_{\text {dislocation }}^{(h k l)}=r^{(h k l)}$ $\left.r_{\text {bulk }}^{(h k l)}\right)$. The results highlight an asymptotic relationship between dissolution rate and dislocation density.

\section{Discussion}

\subsection{Bulk dissolution rate evolution as a function of bond-breaking probabilities}

From the numerical experiments described in Section 3.1, the steady state dissolution rates of enstatite (defined as congruent and constant dissolution rates with time) are proportional to each individual bond-breaking probability raised at a given power inferred from the linear regressions depicted in a log-log diagram (Fig. 2). Moreover, since the slope of the linear regression between $\log \left(P_{i}\right)$ ( $i$ stands for $\mathrm{Mg}-\mathrm{O}-\mathrm{Mg}$ or $\mathrm{Mg}-\mathrm{O}-\mathrm{Si}$ or $\mathrm{Si}-\mathrm{O}-\mathrm{Si}$ ) and $\log (r)$ is constant whatever the difference between the two other involved probabilities; a more general function of the dissolution rate can be written as:

$$
r_{b u l k}^{(h k l)}=k P_{M g-O-M g}^{\alpha} P_{M g-O-S i}^{\beta} P_{S i-O-S i}^{\gamma}
$$

where $k$ is a constant and $\alpha, \beta, \gamma$ are the corresponding slopes listed in Table 2 for the various regressions. The parameter $k$ is then obtained using equation 5 and is constant for each face. The different parameter values are summarized in Table 2, the $\alpha, \beta, \gamma$ values are obtained by 
taking the average values of the corresponding slopes and the dissolution rates calculated with the surrogate model (Eq. 5) are compared with the simulated one in Fig. 5.

\begin{tabular}{lllll}
\hline Face & $k$ & $\alpha$ & $\beta$ & $\gamma$ \\
\hline$(100)$ & 8.87 & 2.46 & 4.62 & 0.94 \\
$(010)$ & 7.80 & 2.22 & 4.65 & 0.75 \\
$(001)$ & 4.72 & 6.36 & 4.19 & 0.14
\end{tabular}

Table 2. Values of the different face-specific parameters of the surrogate model.

If the parameter $\alpha$ can be considered as constant for (100) and (010) faces (Table 1), the slope that corresponds to a variation of $\mathrm{P}_{\mathrm{Mg}-\mathrm{O}-\mathrm{Mg}}$ decreases from 7.46 to 5.05 when the difference between EMg-O-Si and ESi-O-Si decreases, i.e., when EMg-O-Si gets closer to ESi-O-Si. For these cases, the assumptions used in the concept of the surrogate model may not be fulfilled (e.g., $k$ is constant and does not depend on the different probabilities). This assumption will be discussed in the next section. Despite this approximation and the apparent trend for the (001) face, the proposed model described by Eq. 5 is capable of satisfactorily estimating the simulated dissolution rates (Fig. 5) for the three different faces. Note that Eq. (5) has been derived from simulations where only the first coordination sphere of surface atoms is considered for expressing the dissolution probability of individual atoms. Several studies ${ }^{36,64}$ have shown that second coordination sphere may also play a role in the dissolution, and may impact the shape of the developed etch pits. However, we showed that considering only the first coordination sphere is enough to reproduce satisfactorily the face-specific shape of etch pits observed on enstatite ${ }^{41}$, explaining why we stick to this model in the present study.

302 Considering the impact of the second coordination sphere would make Eq. 5 more 303 sophisticated, since it would probably incorporate specific terms related to the second coordination spheres. 
The development of the surrogate expression given in Eq. 5 is derived from a

307

308 statistical analysis of the outputs of the stochastic simulations of enstatite dissolution, with no preconception of the mathematical form that should be used to relate the steady-state dissolution rates to the individual bond-breaking probabilities describing enstatite hydrolysis. In the present section, we provide a possible theoretical explanation of Eq. 5.

The dissolution rate can be defined as the derivative of the number of atoms that are dissolved with time:

$$
r=\frac{d N_{M, d}}{d t}
$$

where $N_{M, d}$ stands for the amount of dissolved atoms belonging to the $\mathrm{M}$ species during the time interval $d t$. Arguably, $N_{M, d}$ should depend on two parameters: the amount of atoms located at the mineral surface $\left(N_{M, S}\right)$ and the intrinsic detachment rate of these atoms. Importantly, classical theories of dissolution kinetics suggest that at steady-state conditions, $N_{M, S}$ is constant and proportional to the considered surface area ${ }^{6}$. This aspect was numerically verified in our previous study ${ }^{41}$ where we showed that the amount of surface atoms level to a plateau as soon as the dissolution becomes congruent and the dissolution rate is constant.

At steady state, the number of dissolved atoms of $\mathrm{Mg}$ or $\mathrm{Si}$ is given by:

$$
N=\hat{N}_{M g} P_{M g}=\hat{N}_{S i} P_{S i}
$$

where $N$ is the number of dissolved atoms of $\mathrm{Mg}$ or $\mathrm{Si}, \hat{N}_{A}$ is the number of atoms $\mathrm{A}(\mathrm{Mg}$ or $\mathrm{Si}$ ) at the mineral surface, $P_{A}$ is the probability that atom $\mathrm{A}$ is dissolved. Following the previous equation, $N$ can be rewritten as:

$$
N=\sqrt{\hat{N}_{M g} P_{M g} \hat{N}_{S i} P_{S i}}
$$



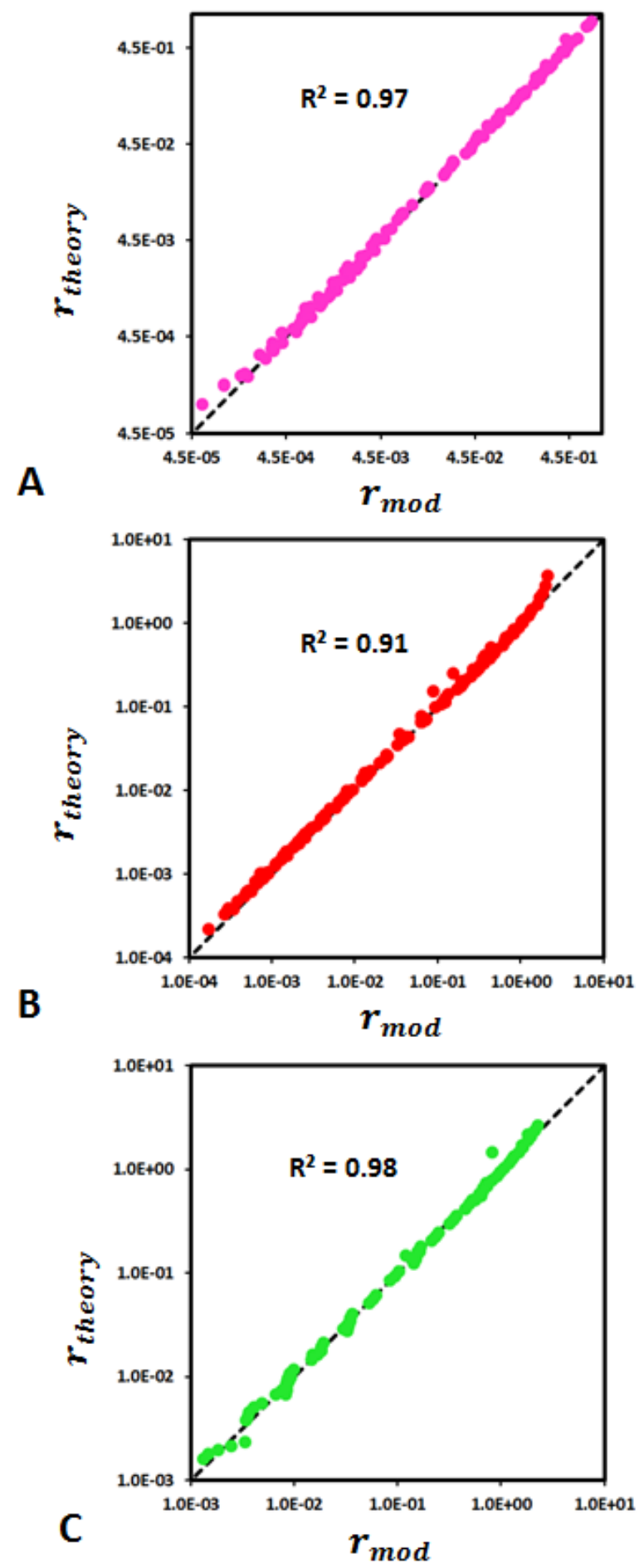

Fig 5. Comparison between the dissolution rates estimated with the surrogate model ( $r_{\text {theory }}$; Eq. 5) and dissolution rates provided by the numerical simulations $\left(r_{m o d}\right)$ for faces (100) (A), (010) (B) and (001) (C). The comparison is made for all the different simulations listed in Table 1. For instance, (A) presents all the simulations shown in Fig. 2, and the rate variability results from the corresponding bond-breaking probabilities that are reported in Table 1.

The dissolution of an A atom for a given coordination sphere $i$ is given by:

$$
P_{A, i}=P_{A-A}^{\alpha_{i}} P_{A-B}^{\beta_{i}}
$$


where $\alpha_{i}$ and $\beta_{i}$ are the number of bonds connecting the considered A atom to another $\mathrm{A}$ or to a $\mathrm{B}$ atom ( $\mathrm{Si}$ or $\mathrm{Mg}$ accordingly), respectively. At the solid surface, we consider that there are $N_{C}$ different coordination spheres and $n_{i}$ atoms with a coordination sphere $i$. Therefore, the probability to dissolve the atom A over the mineral face is:

$$
P_{A}=\frac{1}{\hat{N}_{A}} \sum_{i=1}^{N_{C}} n_{i} P_{A-A}^{\alpha_{i}} P_{A-B}^{\beta_{i}} \text { and } \hat{N}_{A}=\sum_{i=1}^{N_{C}} n_{i}
$$

329

Or

$$
P_{A}=\frac{1}{\hat{N}_{A}}\left(\sum_{i=1}^{N_{C}} n_{i} P_{A-A}^{\alpha_{i}-\alpha_{A}} P_{A-B}^{\beta_{i}-\beta_{A}}\right) P_{A-A}^{\alpha_{A}} P_{A-B}^{\beta_{A}}=k_{A} P_{A-A}^{\alpha_{A}} P_{A-B}^{\beta_{A}}
$$

330 with

$$
k_{A}=\frac{1}{\hat{N}_{A}} \sum_{i=1}^{N_{C}} n_{i} P_{A-A}^{\alpha_{i}-\alpha_{A}} P_{A-B}^{\beta_{i}-\beta_{A}}
$$

331 and the number of dissolved atoms is:

$$
\begin{aligned}
N & =\sqrt{\hat{N}_{M g} \hat{N}_{S i}} \sqrt{k_{M g} P_{M g O M g}^{\alpha_{M g}} P_{M g O S i}^{\beta_{M g}} k_{S i} P_{S i O S i}^{\alpha_{S i}} P_{M g O S i}^{\beta_{S i}}} \\
& =\sqrt{\hat{N}_{M g} k_{M g} \hat{N}_{S i} k_{S i}} P_{M g O M g}^{\alpha} P_{M g O S i}^{\beta} P_{S i O S i}^{\gamma}
\end{aligned}
$$

332 with $\alpha=\alpha_{M g}, \beta=\beta_{M g}+\beta_{S i}, \gamma=\alpha_{S i}$.

333 The statistical analysis of the numerical experiments provides some values of the parameters $k, \alpha, \beta, \gamma$ (see Table 2). Surprisingly, the parameter $k$ does not depend on the probabilities $P_{A-A}$ and $P_{A-B}$ in the range of the numerical values used for the experiments. An appropriate 336 choice of $\left(\alpha_{A}, \beta_{A}\right)$ may explain this property. Assuming that $\alpha_{A}=\alpha_{j}$ and $\beta_{A}=\beta_{j}$, the 337 constant $k_{A}$ can be rewritten as:

$$
k_{A}=\frac{n_{j}}{\hat{N}_{A}}+\frac{1}{\hat{N}_{A}} \sum_{i=1, i \neq j}^{N_{C}} n_{i} P_{A-A}^{\alpha_{i}-\alpha_{j}} P_{A-B}^{\beta_{i}-\beta_{j}}
$$


338 Therefore, $k_{A}$ can be a constant value if $n_{j} \gg \sum_{i=1, i \neq j}^{N_{C}} n_{i} P_{A-A}^{\alpha_{i}-\alpha_{j}} P_{A-B}^{\beta_{i}-\beta_{j}}$ which is possible when $\alpha_{i}>\alpha_{j}$ and/or $\beta_{i}>\beta_{j}$, for having positive exponents for the probabilities $P_{A-A}$ and/or $P_{A-B}$.

340 Given that the exponents are positive, considering $k$ as a constant is a reasonable assumption

341 if the difference between $P_{A-A}$ and $P_{A-B}$ is significant. The validity of this condition is 342 difficult to appreciate if $P_{A-A}$ and $P_{A-B}$ are close, as it is the case for the simulations run for 343 (001) face (see section 4.1 and Table 1). Finally, this demonstrates that the dissolution rate is therefore compatible with Eq. 5:

$$
r=W \frac{N}{d t}=W \frac{k P_{M g-O-M g}^{\alpha} P_{M g-O-S i}^{\beta} P_{S i-O-S i}^{\gamma}}{d t} \text { with } W=\frac{V_{c e l l}}{i t e r \times N_{c m x} \times S}
$$

with $N_{c m x}$ standing for the number of "complexes" (see 4.4) in the enstatite cell.

\subsection{Accounting for the impact of dislocation density on the dissolution rates}

Dislocations have a measurable impact on the dissolution rate, whatever the set of probabilities that was tested (Fig 6C). This result is consistent with numerical and experimental studies that showed that the presence of dislocations outcropping at mineral surfaces globally increases the dissolution rate when the nucleation of etch pits is thermodynamically favorable (i.e., at far-from-equilibrium conditions $11,14,16,23,31,37$ ). However, when dealing with natural samples, the dislocation density remains a parameter impossible or difficult to control a priori, which complicates the prediction of its impact on dissolution rate. Furthermore, several studies showed that the mineral dissolution rate is not a strictly increasing function of the dislocation density ${ }^{31,37,80}$ since above a given threshold, the dissolution rate no longer varies with the dislocation density. 
and the additional dissolution rate resulting from etch pit opening at dislocation outcrop (see Section 3.3.), which verifies that the dissolution rate levels to a plateau value when the dislocation density tends towards infinity:

$$
r_{\text {dislocation }}^{(100)}=k_{a p p}\left(1-e^{-\frac{\rho_{d}}{\omega}}\right)
$$

where $k_{\text {app }}$ and $\omega\left(\approx 5.51 \times 10^{10}\right)$ are empirical parameters that were obtained by calibration on the outputs of the simulations, and $\rho_{d}$ is the dislocation density. Whereas $\omega$ does not seem to vary with the probabilities used as input parameters, it clearly appears that $k_{a p p}$ (Fig. 4) depends on the individual bond-breaking probabilities. From a physical standpoint, this observation may result from the fact the first coordination spheres of atoms in the vicinity of a dislocation line differ from those of atoms considered for defect-free surface.

Considering this apparent relationship between $k_{a p p}$ and the probabilities, a first tentative to link the global rate to the probabilities and the dislocation density was performed using the same exponent for each probability as the "bulk" case. Since the global rate is equivalent to $r^{(h k l)}=r_{\text {dislocation }}^{(h k l)}+r_{\text {bulk }}^{(h k l)}$, it is possible to assume the following relation:

$$
r^{(h k l)}=\left[k+k_{d i s}\left(1-e^{-\frac{\rho_{d}}{\omega}}\right)\right] P_{M g-O-M g}^{\alpha} P_{M g-O-S i}^{\beta} P_{S i-O-S i}^{\gamma}
$$

A comparison between this relation and the experimental results is given in Fig. 6A and the value of $k_{d i s}$ is given in Table 3. Although the relationship between the surrogate model and the results of the simulations was proven efficient to simulate the dissolution of defect-free surfaces $\left(\mathrm{R}^{2}>0.9\right.$ in all cases), it is not the case when using Eq. 17, for which $\mathrm{R}^{2}=0.76$.

In order to improve the agreement between the surrogate model of the global rate and the results of the simulations, numerical experiments were run for face (100) with dislocations similarly to Section 4.1. The dissolution rates were fitted using the following function: 


$$
r_{\text {dislocation }}^{(h k l)}=k_{\text {dis }} k P_{M g-O-M g}^{\alpha_{d i s}} P_{M g-O-S i}^{\beta_{d i s}} P_{S i-O-S i}^{\gamma_{d i s}}\left(1-e^{-\frac{\rho_{d}}{\omega}}\right)
$$

380 The values of $\alpha_{d i s}, \beta_{d i s}, \gamma_{\text {dis }}$ are lower than those obtained in the "bulk" (defect-free) case 381 (Table 3), which makes sense since the coordination spheres of atoms are arguably lower in the vicinity of the dislocation line, resulting in greater measured dissolution rates.

\begin{tabular}{ccccc}
\hline $\boldsymbol{k}_{\text {dis }}$ & $\alpha_{\text {dis }}$ & $\beta_{\text {dis }}$ & $\gamma_{\text {dis }} \gamma$ & $\mathbf{R}^{\mathbf{2}}$ \\
\hline $\mathbf{2 2 7 . 9}$ & $\mathbf{2 . 4 6}$ & $\mathbf{4 . 6 2}$ & $\mathbf{0 . 9 4}$ & 0.72 \\
$\mathbf{4 4 . 7}$ & 2.09 & 4.09 & 0.67 & 0.86 \\
\hline
\end{tabular}

Table 3. Values of the parameters of the model described by Eq. 17 and Eq. 18 and the correlation coefficient $\mathrm{R}^{2}$. The bold characters represent the fitted parameters.

387 The global dissolution rate of enstatite can then be calculated by summing $r_{\text {bulk }}^{(h k l)}$ and $388 r_{\text {dislocation }}^{(h k l)}$, resulting in the following relation:

$$
r^{(h k l)}=k P_{M g-O-M g}^{\alpha} P_{M g-O-S i}^{\beta} P_{S i-O-S i}^{\gamma}+k_{d i s} P_{M g-O-M g}^{\alpha_{d i s}} P_{M g-O-S i}^{\beta_{d i s}} P_{S i-O-S i}^{\gamma_{d i s}}\left(1-e^{-\frac{\rho_{d}}{\omega}}\right)
$$

Therefore, the agreement between the results of the simulations and the surrogate model is improved and its correlation coefficient increases from 0.72 to 0.86 (Fig. 6B).

If this type of relations can be extended to other minerals and other types of defects (e.g. vacancies), they may represent an interesting method to link together dissolution rates derived from considerations at the atomic scale and those derived from observations at the mineral scale. This type of relations can also represent a significant progress for reactive transport models that simulate steady-state dissolution reactions. Indeed, even though the present work represents a preliminary step to link relations at the atomic scale to macroscopic dissolution rates, it shows promise as a mean to express face-specific steady-state dissolution rates as a function of the bond-breaking probabilities (and therefore, of the activation energies of hydrolysis) of the different types of bonds that exist for a given mineral. While some studies have questioned the possibility to use the outputs of Monte Carlo simulations in 
reactive-transport codes because of the limited space- and time-scales investigated following such stochastic treatments of the dissolution process, here we show that steady-state dissolution rates may be satisfactorily calculated from considerations at the atomic scale. As a consequence, rate equations similar to Eq. 17 or Eq. 19 may be simply implemented in reactive transport codes as the rate-constant of the source term of the classical reactionadvection-diffusion equation. This may be of interest for modeling processes for which the

407 fluid composition can be considered as unchanged over the considered simulated time, such
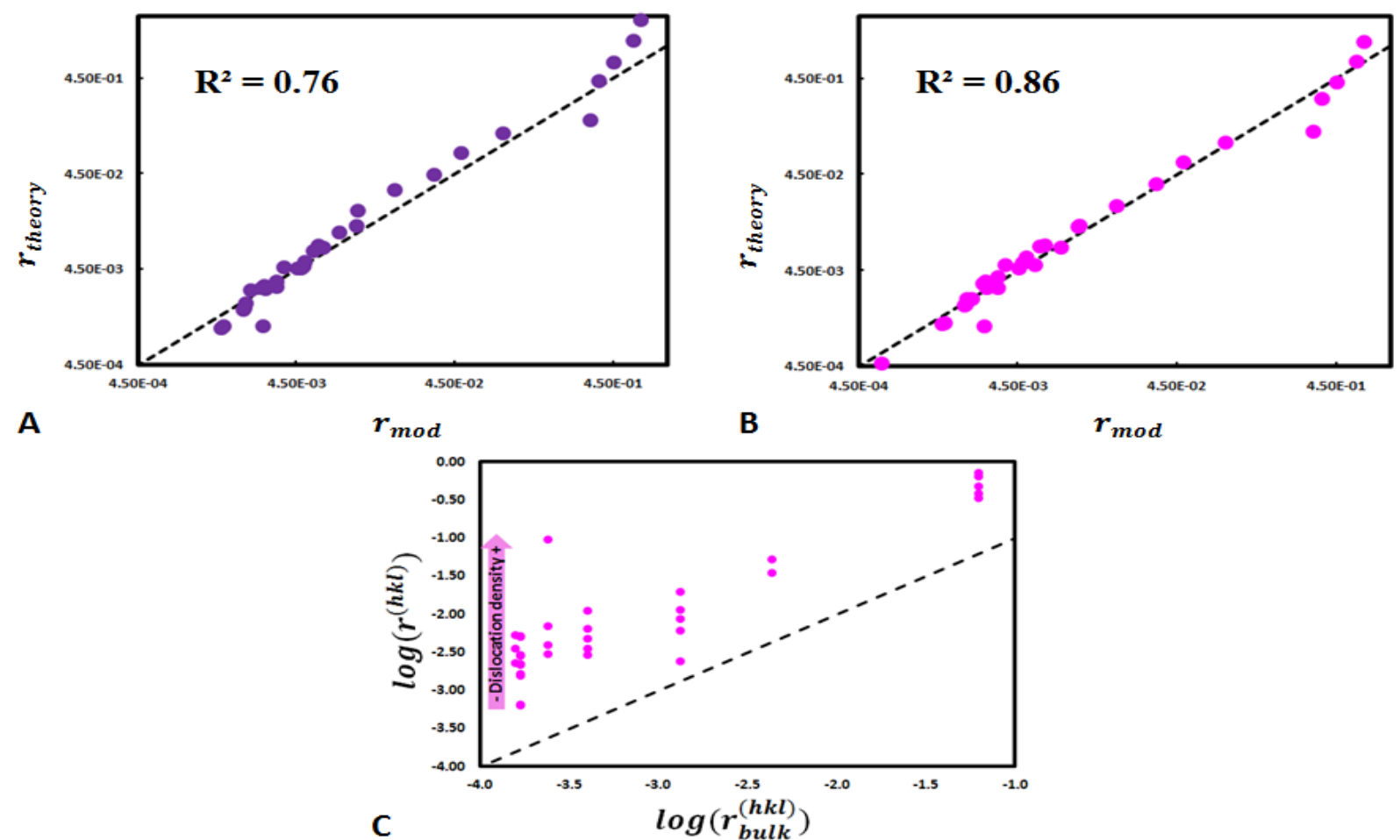

Figure 6. Comparison of experimental dissolution rates $\left(r_{m o d}\right)$ and dissolution rates determined with the surrogate model $\left(r_{\text {theory }}\right)$ with the presence of one dislocation (dislocation density is changed by varying the surface area). Agreement using (A) Eq. 17 and (B) Eq. 19. (C) Comparison between dislocation-driven dissolution and bulk (dislocation-free) dissolution. The presence of dislocations increases dissolution rates for all the simulations. The data points represent the simulations conducted using sets of probabilities and dislocation densities given in Table 4 . 
412 pyroxene group (there is a priori no reason to think so), as well as expanding the relation to

413 the transient regime, where the dissolution rate is neither stoichiometric nor constant. As long 414 as this latter task remains not fulfilled, alternate approaches such as the use of Voronoi 415 distance maps ${ }^{39,73}$ probably represents the most promising compromise to upscale kinetic 416 Monte Carlo simulations. This strategy nonetheless remains far more complicated than just 417 using a surrogate expression as proposed above.

\begin{tabular}{cccc}
\hline $\begin{array}{c}\text { Dislocation } \\
\text { density }\end{array}$ & MgOMg & MgOSi & SiOSi \\
\hline $\mathbf{1 . 9 9 E}+\mathbf{1 1}$ & $\mathbf{0 . 9 9}$ & $\mathbf{0 . 3}$ & $\mathbf{0 . 0 1 0 9}$ \\
$\mathbf{1 . 9 9 E}+\mathbf{1 1}$ & $\mathbf{0 . 9 9}$ & $\mathbf{0 . 2 5}$ & $\mathbf{0 . 0 0 9 6}$ \\
$1.99 \mathrm{E}+11$ & 0.99 & 0.9 & 0.0096 \\
$\mathbf{1 . 9 9 E}+\mathbf{1 1}$ & $\mathbf{0 . 9 9}$ & $\mathbf{0 . 2 5}$ & $\mathbf{0 . 0 0 9 1}$ \\
$1.99 \mathrm{E}+11$ & 0.99 & 0.25 & 0.0669 \\
$\mathbf{4 . 8 8 E}+\mathbf{1 0}$ & $\mathbf{0 . 9 9}$ & $\mathbf{0 . 3}$ & $\mathbf{0 . 0 1 0 9}$ \\
$\mathbf{4 . 8 8 E}+\mathbf{1 0}$ & $\mathbf{0 . 9 9}$ & $\mathbf{0 . 2 5}$ & $\mathbf{0 . 0 0 9 6}$ \\
$4.88 \mathrm{E}+10$ & 0.99 & 0.9 & 0.0096 \\
$\mathbf{4 . 8 8 E}+\mathbf{1 0}$ & $\mathbf{0 . 9 9}$ & $\mathbf{0 . 2 5}$ & $\mathbf{0 . 0 0 9 1}$ \\
$4.88 \mathrm{E}+10$ & 0.99 & 0.25 & 0.0669 \\
$\mathbf{2 . 2 1 E}+\mathbf{1 0}$ & $\mathbf{0 . 9 9}$ & $\mathbf{0 . 3}$ & $\mathbf{0 . 0 1 0 9}$ \\
$\mathbf{2 . 2 1 E}+\mathbf{1 0}$ & $\mathbf{0 . 9 9}$ & $\mathbf{0 . 2 5}$ & $\mathbf{0 . 0 0 9 6}$ \\
$2.21 \mathrm{E}+10$ & 0.99 & 0.9 & 0.0096 \\
$\mathbf{2 . 2 1 E}+\mathbf{1 0}$ & $\mathbf{0 . 9 9}$ & $\mathbf{0 . 2 5}$ & $\mathbf{0 . 0 0 9 1}$ \\
$2.21 \mathrm{E}+10$ & 0.99 & 0.25 & 0.0669 \\
$\mathbf{1 . 2 1 E}+\mathbf{1 0}$ & $\mathbf{0 . 9 9}$ & $\mathbf{0 . 3}$ & $\mathbf{0 . 0 1 0 9}$ \\
$\mathbf{1 . 2 1 E}+\mathbf{1 0}$ & $\mathbf{0 . 9 9}$ & $\mathbf{0 . 2 5}$ & $\mathbf{0 . 0 0 9 6}$ \\
$1.21 \mathrm{E}+10$ & 0.99 & 0.9 & 0.0096 \\
$\mathbf{1 . 2 1 E}+\mathbf{1 0}$ & $\mathbf{0 . 9 9}$ & $\mathbf{0 . 2 5}$ & $\mathbf{0 . 0 0 9 1}$ \\
$1.21 \mathrm{E}+10$ & 0.99 & 0.25 & 0.0669 \\
$\mathbf{3 . 0 0 E}+\mathbf{0 9}$ & $\mathbf{0 . 9 9}$ & $\mathbf{0 . 3}$ & $\mathbf{0 . 0 1 0 9}$ \\
$\mathbf{3 . 0 0 E}+\mathbf{0 9}$ & $\mathbf{0 . 9 9}$ & $\mathbf{0 . 2 5}$ & $\mathbf{0 . 0 0 9 6}$ \\
$3.00 \mathrm{E}+09$ & 0.99 & 0.9 & 0.0096 \\
$\mathbf{3 . 0 0 E}+\mathbf{0 9}$ & $\mathbf{0 . 9 9}$ & $\mathbf{0 . 2 5}$ & $\mathbf{0 . 0 0 9 1}$ \\
$3.00 \mathrm{E}+09$ & 0.99 & 0.25 & 0.0669 \\
$1.9899 \mathrm{E}+11$ & 0.99 & 0.5 & 0.0096 \\
$1.9899 \mathrm{E}+11$ & 0.8 & 0.3 & 0.0109 \\
$1.9899 \mathrm{E}+11$ & 0.7 & 0.3 & 0.0109 \\
$4.8773 \mathrm{E}+10$ & 0.99 & 0.5 & 0.0096 \\
$4.8773 \mathrm{E}+10$ & 0.8 & 0.3 & 0.0109 \\
$4.8773 \mathrm{E}+10$ & 0.7 & 0.3 & 0.0109 \\
$2.211 \mathrm{E}+10$ & 0.99 & 0.5 & 0.0096 \\
$2.211 \mathrm{E}+10$ & 0.8 & 0.3 & 0.0109 \\
$2.211 \mathrm{E}+10$ & 0.7 & 0.3 & 0.0109 \\
\hline & & &
\end{tabular}


Table 4. Dislocation densities and probabilities used in the simulations used for Fig. 5. Bolded lines represent the input parameters used in the simulations shown in Fig. 3.

\subsection{Relation between the coordination of atoms leaving the surface and the surrogate expression}

Interestingly, when atoms are released from the mineral surface, they seem to have a specific average coordination. This assertion is supported by the analysis of the environment of $\mathrm{Mg}$ and $\mathrm{Si}$ when they leave the surface, since the mean values of $\mathrm{Mg}-\mathrm{O}-\mathrm{Mg}, \mathrm{Mg}-\mathrm{O}-\mathrm{Si}+\mathrm{Mg}-$ O-Si and Si-O-Si bonds remain constant and unaffected by the set of probabilities used to run the simulations for all faces (see Section 3.2). However, the numerical values of the parameters used in the surrogate expression of the dissolution rate are face-specific. This apparent paradox can be easily explained by recalling that the histograms reported in Fig. 3 actually take into account all atoms leaving the surface, including those whose departure is not rate-limiting of the dissolution process.

By analogy with Eq. 3, the surrogate expression given by Eq. 17 or Eq. 19 may reflect the average coordination of atoms that control the dissolution process, as kink sites would do. The fact that the numerical values of $\alpha, \beta$ and $\gamma$ are face-specific indicates that this average rate-controlling configuration is not unique for a given mineral. Most likely, this result reflects the fact that kink sites, which are much more difficult to define using a real crystal lattice than simplified isotropic cubic Kossel crystals, differ from one face to another when dealing with anisotropic structures. This explanation would in turn be consistent with the observed anisotropic reactivity of the pyroxene structure.

\section{Conclusion}

In this study, we presented the results of hundreds of probabilistic simulations of enstatite dissolution to link the overall dissolution rate to the bond-breaking probabilities used 
as input parameters. By varying independently each probability, we showed that it is possible to build a surrogate model that links the different probabilities to the dissolution rate following a power law. This result contributes to the general effort of upscaling of mineral dissolution kinetics, since this surrogate expression is based on a mechanistic approach developed from considerations at the atomic-scale, from which the resulting dissolution rate constants can be used as a source term in reactive transport simulations. However, the relation remains valid at steady-state conditions only, and the transient regime must be treated following other upscaling approaches, such as the use of Voronoï distance maps ${ }^{39,73}$. The various simulations conducted with dislocations have shown that it is possible to link the dissolution rate to the dislocation density by introducing an exponential factor to the 455 global $r=f\left(\prod_{i} P_{i}^{z_{i}}\right)$ relation. This relation further extends the interest of probabilistic simulations of mineral dissolution to account for the impact of some important parameters that are hardly controlled in experimental studies. In addition, in case of a bond hydrolysis with significant higher activation energy than the others, the dissolution rate is strongly correlated to this activation energy, and the surrogate model may be used to estimate the value of this parameter.

However, the surrogate model also presents some limitations, particularly when M-O$\mathrm{Si}$ and Si-O-Si hydrolysis probabilities are getting close to each other (where $\mathrm{M}$ is a divalent cation, i.e., $\mathrm{Mg}$ in the case of enstatite). In this specific case, the results may be out of the

464 limits of the theoretical framework that supports the development of the surrogate expression. 465 Of note, such cases are however those for which the input parameters are physically unrealistic, as the activation energy of Si-O-Si hydrolysis is admitted to be much lower than any other M-O-Si bond. 


\section{Acknowledgements}

473

A.B. thanks the University of Strasbourg for funding his $\mathrm{PhD}$ grant. We are also grateful for the careful reviews and detailed suggestions made by two anonymous reviewers, which improved an earlier version of the present paper.

\section{References}

1. Berner, R. A.; Lasaga, A. C.; Garrels, R. M., The Carbonate-Silicate Cycle and Its Effect on Atmospheric Carbon Dioxide over the Past 100 Millions Years. Am J Sci 1983, 284, 641-683.

2. Berner, R. A., A Model for Atmospheric Co2 over Phanerozoic Time. Am J Sci 1991, 291, 339-376.

3. Berner, R. A., 3GEOCARB-II - a Revised Model of Atmospheric Co2 over Phanerozoic Time. Am J Sci 1994, 294, 56-91.

4. Berner, R. A.; Kothavala, Z., GEOCARB III: A Revised Model of Atmospheric Co2 over Phanerozoic Time. Am J Sci 2001, 301, 182-204.

5. Lasaga, A. C., Transition State Theory. In Kinetics of Geochemical Process, Lasaga, A. C., and Kirkpatrick, R.J, Ed. Mineralogical Society of America: 1981; Vol. 8, pp 135-169.

6. Aagaard, P.; Helgeson, H. C., Thermodynamic and Kinetic Constraints on Reaction-Rates among Minerals and Aqueous-Solutions .1. Theoretical Considerations. Am J Sci 1982, 282, 237-285.

7. Oelkers, E. H.; Schott, J.; Devidal, J.-L., The Effect of Aluminum, Ph, and Chemical Affinity on the Rates of Aluminosilicate Dissolution Reactions. Geochim Cosmochim Ac 1994, 58, 2011-2024.

8. Lasaga, A. C., Fundamental Approaches in Describing Mineral Dissolution and Precipitation Rates. In Chemical Weathering Rates of Silicate Minerals, White, A. F.; Brantley, S. L., Eds. Mineralogical Society of America: 1995; Vol. 31, pp 23-86.

9. Gin, S.; Jegou, C.; Frugier, P.; Minet, Y., Theoretical Consideration on the Application of the Aagaard-Helgeson Rate Law to the Dissolution of Silicate Minerals and Glasses. Chem Geol 2008, 255, 14-24.

10. Luttge, A., Crystal Dissolution Kinetics and Gibbs Free Energy. Journal of Electron Spectroscopy and Related Phenomena 2006, 150, 248-259.

11. Burch, T. E.; Nagy, K. L.; Lasaga, A. C., Free Energydependence of Albite Dissolution Kinetics at $80^{\circ} \mathrm{C}$ and $\mathrm{Ph}$ 8.8. Chem Geol 1993, 105, 137-162.

12. Taylor, A. S.; Blum, J. D.; Lasaga, A. C., The Dependence of Labradorite Dissolution and Sr Isotope Release Rates on Solution Saturation State. Geochim Cosmochim Ac 2000, 64, 2389-2400.

13. Beig, M. S.; Luttge, A., Albite Dissolution Kinetics as a Function of Distance from Equilibrium: Implications for Natural Feldspar Weathering. Geochim Cosmochim Ac 2006, 70, $1402-$ 1420. 
14. Hellmann, R.; Tisserand, D., Dissolution Kinetics as a Function of the Gibbs Free Energy of Reaction: An Experimental Study Based on Albite Feldspar. Geochim Cosmochim Ac 2006, 70, 364 383.

15. Dixit, S.; Carroll, S. A., Effect of Solution Saturation State and Temperature on Diopside Dissolution. Geochemical Transactions 2007, 8 .

16. Arvidson, R. S.; Luttge, A., Mineral Dissolution Kinetics as a Function of Distance from Equilibrium - New Experimental Results. Chem Geol 2010, 269, 79-88.

17. Daval, D.; Hellmann, R.; Corvisier, J.; Tisserand, D.; Martinez, I.; Guyot, F., Dissolution Kinetics of Diopside as a Function of Solution Saturation State: Macroscopic Measurements and Implications for Modeling of Geological Storage of Co2. Geochim Cosmochim Ac 2010, 74, 26152633.

18. Nicoleau, L.; Nonat, A.; Perrey, D., The Di- and Tricalcium Silicate Dissolutions. Cement and Concrete Research 2013, 47, 14-30.

19. Pollet-Villard, M.; Daval, D.; Ackerer, P.; Saldi, G. D.; Wild, B.; Knauss, K. G.; Fritz, B., Does Crystallographic Anisotropy Prevent the Conventional Treatment of Aqueous Mineral Reactivity? A Case Study Based on K-Feldspar Dissolution Kinetics. Geochim Cosmochim Ac 2016, 190, 294-308.

20. Fischer, C.; Arvidson, R. S.; Lüttge, A., How Predictable Are Dissolution Rates of Crystalline Material? Geochim Cosmochim Ac 2012, 98, 177-185.

21. Godinho, J. R. A.; Piazolo, S.; Evins, L. Z., Effect of Surface Orientation on Dissolution Rates and Topography of Caf2. Geochim Cosmochim Ac 2012, 86, 392-403.

22. Daval, D.; Hellmann, R.; Saldi, G. D.; Wirth, R.; Knauss, K. G., Linking Nm-Scale Measurements of the Anisotropy of Silicate Surface Reactivity to Macroscopic Dissolution Rate Laws: New Insights Based on Diopside. Geochim Cosmochim Ac 2013, 107, 121-134.

23. Smith, M. E.; Knauss, K. G.; Higgins, S. R., Effects of Crystal Orientation on the Dissolution of Calcite by Chemical and Microscopic Analysis. Chem Geol 2013, 360-361, 10-21.

24. Wild, B.; Daval, D.; Guyot, F.; Knauss, K. G.; Pollet-Villard, M.; Imfeld, G., Ph-Dependent Control of Feldspar Dissolution Rate by Altered Surface Layers. Chem Geol 2016, 442, 148-159.

25. Kurganskaya, I.; Luttge, A., Kinetic Monte Carlo Approach to Study Carbonate Dissolution. The Journal of Physical Chemistry C 2016, 120, 6482-6492.

26. Daval, D.; Bernard, S.; Rémusat, L.; Wild, B.; Guyot, F.; Micha, J. S.; Rieutord, F.; Magnin, V.; Fernandez-Martinez, A., Dynamics of Altered Surface Layer Formation on Dissolving Silicates. Geochim Cosmochim Ac 2017, 209, 51-69.

27. Fischer, C.; Luttge, A., Pulsating Dissolution of Crystalline Matter. Proceedings of the National Academy of Sciences 2018, 115, 897-902.

28. Zhang, L.; Lüttge, A., Aluminosilicate Dissolution Kinetics: A General Stochastic Model. The Journal of Physical Chemistry B 2008, 112, 1736-1742.

29. Brantley, S. L.; Crane, S. R.; Crerar, D. A.; Hellmann, R.; Stallard, R., Dissolution at Dislocation Etch Pits in Quartz. Geochim Cosmochim Ac 1986, 50, 2349-2361.

30. Lasaga, A. C.; Blum, A. E., Surface Chemistry, Etch Pits and Mineral-Water Reactions. Geochim Cosmochim Ac 1986, 50, 2363-2379.

31. Lasaga, A. C.; Luttge, A., Variation of Crystal Dissolution Rate Based on a Dissolution Stepwave Model. Science 2001, 291, 2400-2404.

32. Bouissonnié, A.; Daval, D.; Marinoni, M.; Ackerer, P., From Mixed Flow Reactor to Column Experiments and Modeling: Upscaling of Calcite Dissolution Rate. Chem Geol 2018, 487, 63-75.

33. Amelinckx, S., The Direct Observation of Dislocations. Solid State Physics 1964.

34. Teng, H. H., Controls by Saturation State on Etch Pit Formation During Calcite Dissolution. Geochim Cosmochim Ac 2004, 68, 253-262.

35. Kurganskaya, I.; Arvidson, R. S.; Fischer, C.; Luttge, A., Does the Stepwave Model Predict Mica Dissolution Kinetics? Geochim Cosmochim Ac 2012, 97, 120-130.

36. Kurganskaya, I.; Luttge, A., A Comprehensive Stochastic Model of Phyllosilicate Dissolution: Structure and Kinematics of Etch Pits Formed on Muscovite Basal Face. Geochim Cosmochim Ac 2013, 120, 545-560. 
37. Pollet-Villard, M.; Daval, D.; Fritz, B.; Knauss, K. G.; Schäfer, G.; Ackerer, P., Influence of Etch Pit Development on the Surface Area and Dissolution Kinetics of the Orthoclase (001) Surface. Chem Geol 2016, 447, 79-92.

38. Perez, A.; Daval, D.; Fournier, M.; Vital, M.; Delaye, J.-M.; Gin, S., Comparing the Reactivity of Glasses with Their Crystalline Equivalents: The Case Study of Plagioclase Feldspar. Geochim Cosmochim Ac 2019, 254, 122-141.

39. Luttge, A.; Arvidson, R. S.; Fischer, C.; Kurganskaya, I., Kinetic Concepts for Quantitative Prediction of Fluid-Solid Interactions. Chem Geol 2019, 504, 216-235.

40. Trindade Pedrosa, E.; Kurganskaya, I.; Fischer, C.; Luttge, A., A Statistical Approach for Analysis of Dissolution Rates Including Surface Morphology. Minerals 2019, 9, 458.

41. Bouissonnié, A.; Daval, D.; Guyot, F.; Ackerer, P., The Dissolution Anisotropy of Pyroxenes: Experimental Validation of a Stochastic Dissolution Model Based on Enstatite Dissolution. The Journal of Physical Chemistry C 2020, 124, 3122-3140.

42. Schott, J.; Berner, R. A., X-Ray Photoelectron Studies of the Mechanism of Iron Silicate Dissolution During Weathering. Geochim Cosmochim Ac 1983, 47, 2233-2240.

43. Eggleston, C. M.; Hochella, M. F.; Parks, G. A., Sample Preparation and Aging Effects on the Dissolution Rate and Surface-Composition of Diopside. Geochim Cosmochim Ac 1989, 53, 797-804.

44. Gratz, A. J.; Manne, S.; Hansma, P. K., Atomic Force Microscopy of Atomic-Scale Ledges and Etch Pits Formed During Dissolution of Quartz. Science 1991, 251, 1343-1346.

45. Jordan, G.; Rammensee, W., Dissolution Rates and Activation Energy for Dissolution of Brucite (001) : A New Method Based on the Microtopography of Crystal Surfaces. Geochim Cosmochim Ac 1996, 60, 5055-5062.

46. Lüttge, A.; Bolton, E. W.; Lasaga, A. C., An Interferometric Study of the Dissolution Kinetics of Anorthite; the Role of Reactive Surface Area. Am J Sci 1999, 299, 652-678.

47. Wirth, R., Focused Ion Beam (Fib): A Novel Technology for Advanced Application of Microand Nanoanalysis in Geosciences and Applied Mineralogy. Eur J Mineral 2004, 16, 863-876.

48. Cailleteau, C.; Angeli, F.; Devreux, F.; Gin, S.; Jestin, J.; Jollivet, P.; Spalla, O., Insight into Silicate-Glass Corrosion Mechanisms. Nature Materials 2008, 7, 978-983.

49. Noiriel, C., Resolving Time-Dependent Evolution of Pore-Scale Structure, Permeability and Reactivity Using X-Ray Microtomography. Reviews in Mineralogy and Geochemistry 2015, 80, 247 285.

50. Hellmann, R.; Cotte, S.; Cadel, E.; Malladi, S.; Karlsson, L. S.; Lozano-Perez, S.; Cabié, M.; Seyeux, A., Nanometre-Scale Evidence for Interfacial Dissolution-Reprecipitation Control of Silicate Glass Corrosion. Nat Mater 2015, 14, 307-311.

51. Leonard, D. N.; Hellmann, R., Exploring Dynamic Surface Processes During Silicate Mineral (Wollastonite) Dissolution with Liquid Cell Tem. Journal of microscopy 2017, 265, 358-371.

52. Ruiz-Agudo, E.; King, H. E.; Patiño-López, L. D.; Putnis, C. V.; Geisler, T.; RodriguezNavarro, C.; Putnis, A., Control of Silicate Weathering by Interface-Coupled Dissolution-Precipitation Processes at the Mineral-Solution Interface. Geology 2016, 44, 567-570.

53. Geisler, T.; Dohmen, L.; Lenting, C.; Fritzsche, M. B. K., Real-Time in Situ Observations of Reaction and Transport Phenomena During Silicate Glass Corrosion by Fluid-Cell Raman Spectroscopy. Nature Materials 2019, 18, 342-348.

54. Xiao, Y.; Lasaga, A. C., Ab Initio Quantum Mechanical Studies of the Kinetics and Mechanisms of Silicate Dissolution: $\mathrm{H}+(\mathrm{H} 3 \mathrm{o}+)$ Catalysis. Geochim Cosmochim Ac 1994, 58, 53795400 .

55. Pelmenschikov, A.; Strandh, H.; Pettersson, L. G.; Leszczynski, J., Lattice Resistance to Hydrolysis of Si- O- Si Bonds of Silicate Minerals: Ab Initio Calculations of a Single Water Attack onto the (001) and (111) B-Cristobalite Surfaces. The Journal of Physical Chemistry B 2000, 104, $5779-5783$.

56. Criscenti, L. J.; Kubicki, J. D.; Brantley, S. L., Silicate Glass and Mineral Dissolution: Calculated Reaction Paths and Activation Energies for Hydrolysis of a Q(3) Si by H3o+ Using $\mathrm{Ab}$ Initio Methods. Journal of Physical Chemistry A 2006, 110, 198-206.

57. Morrow, C. P.; Nangia, S.; Garrison, B. J., Ab Initio Investigation of Dissolution Mechanisms in Aluminosilicate Minerals. The Journal of Physical Chemistry A 2009, 113, 1343-1352. 
58. Morrow, C. P.; Kubicki, J. D.; Mueller, K. T.; Cole, D. R., Description of Mg2+ Release from Forsterite Using Ab Initio Methods. The Journal of Physical Chemistry C 2010, 114, 5417-5428.

59. Morrow, C. P.; Olsen, A. A.; Kubicki, J. D., Quantum Mechanical Modeling of Hydrolysis and H2o-Exchange in Mg-, Ca-, and Ni-Silicate Clusters: Implications for Dissolution Mechanisms of Olivine Minerals. Am Mineral 2014, 99, 2303-2312.

60. Lasaga, A. C.; Luttge, A., Mineralogical Approaches to Fundamental Crystal Dissolution Kinetics - Dissolution of an a(3)B Structure. Eur J Mineral 2004, 16, 713-729.

61. Devreux, F.; Ledieu, A.; Barboux, P.; Minet, Y., Leaching of Borosilicate Glasses. Ii. Model and Monte-Carlo Simulations. Journal of Non-Crystalline Solids 2004, 343, 13-25.

62. Zhang, L.; Lüttge, A., Al, Si Order in Albite and Its Effect on Albite Dissolution Processes: A Monte Carlo Study. Am Mineral 2007, 92, 1316-1324.

63. Meakin, P.; Rosso, K. M., Simple Kinetic Monte Carlo Models for Dissolution Pitting Induced by Crystal Defects. The Journal of Chemical Physics 2008, 129, 204106.

64. Kurganskaya, I.; Luttge, A., Kinetic Monte Carlo Simulations of Silicate Dissolution: Model Complexity and Parametrization. The Journal of Physical Chemistry C 2013, 117, 24894-24906.

65. Briese, L.; Arvidson, R. S.; Luttge, A., The Effect of Crystal Size Variation on the Rate of Dissolution - a Kinetic Monte Carlo Study. Geochim Cosmochim Ac 2017, 212, 167-175.

66. de Assis, T. A.; Aarão Reis, F. D. A., Dissolution of Minerals with Rough Surfaces. Geochim Cosmochim Ac 2018, 228, 27-41.

67. Lasaga, A. C.; Luttge, A., Mineralogical Approaches to Fundamental Crystal Dissolution Kinetics. Am Mineral 2004, 89, 527-540.

68. Zhang, L.; Luttge, A., Morphological Evolution of Dissolving Feldspar Particles with Anisotropic Surface Kinetics and Implications for Dissolution Rate Normalization and Grain Size Dependence: A Kinetic Modeling Study. Geochim Cosmochim Ac 2009, 73, 6757-6770.

69. Suarez, D.; Wood, J., Short-and Long-Term Weathering Rates of a Feldspar Fraction Isolated from an Arid Zone Soil. Chem Geol 1996, 132, 143-150.

70. Lüttge, A.; Arvidson, R. S.; Fischer, C., A Stochastic Treatment of Crystal Dissolution Kinetics. Elements 2013, 9, 183-188.

71. Knauss, K. G.; Johnson, J. W.; Steefel, C. I., Evaluation of the Impact of Co2, CoContaminant Gas, Aqueous Fluid and Reservoir Rock Interactions on the Geologic Sequestration of Co2. Chem Geol 2005, 217, 339-350.

72. Godderis, Y.; Francois, L. M.; Probst, A.; Schott, J.; Moncoulon, D.; Labat, D.; Viville, D., Modelling Weathering Processes at the Catchment Scale: The Witch Numerical Model. Geochim Cosmochim Ac 2006, 70, 1128-1147.

73. Rohlfs, R.; Fischer, C.; Kurganskaya, I.; Luttge, A., Crystal Dissolution Kinetics Studied by a Combination of Monte Carlo and Voronoi Methods. Minerals 2018, 8, 133.

74. Hugh-Jones, D. A.; J., A. R., A Compressional Study of Mgsio3 Orthoenstatite up to 8.5 Gpa. Am Mineral 1994, 79, 405-410.

75. Bortz, A. B.; Kalos, M. H.; Lebowitz, J. L., A New Algorithm for Monte Carlo Simulation of Ising Spin Systems. Journal of Computational Physics 1975, 17, 10-18.

76. Skrotzki, W., Defect Structure and Deformation Mechanisms in Naturally Deformed Augite and Enstatite. Tectonophysics 1994, 229, 43-68.

77. Fischer, C.; Luttge, A., Beyond the Conventional Understanding of Water-Rock Reactivity. Earth Planet Sc Lett 2017, 457, 100-105.

78. Fischer, C.; Kurganskaya, I.; Luttge, A., Inherited Control of Crystal Surface Reactivity. Appl Geochem 2018, 91, 140-148.

79. Noiriel, C.; Daval, D., Pore-Scale Geochemical Reactivity Associated with Co2 Storage: New Frontiers at the Fluid-Solid Interface. Accounts of Chemical Research 2017, 50, 759-768.

80. Schott, J.; Brantley, S.; Crerar, D.; Guy, C.; Borcsik, M.; Willaime, C., Dissolution Kinetics of Strained Calcite. Geochim Cosmochim Ac 1989, 53, 373-382.

81. Sanjuan, B.; Millot, R.; Dezayes, C.; Brach, M., Main Characteristics of the Deep Geothermal Brine $(5 \mathrm{~km})$ at Soultz-Sous-Forêts (France) Determined Using Geochemical and Tracer Test Data. $\mathrm{Cr}$ Geosci 2010, 342, 546-559. 
669

670

671

672

673

674

675

676

677

678

679

680

681

682

683

684

685 TOC Graphic 


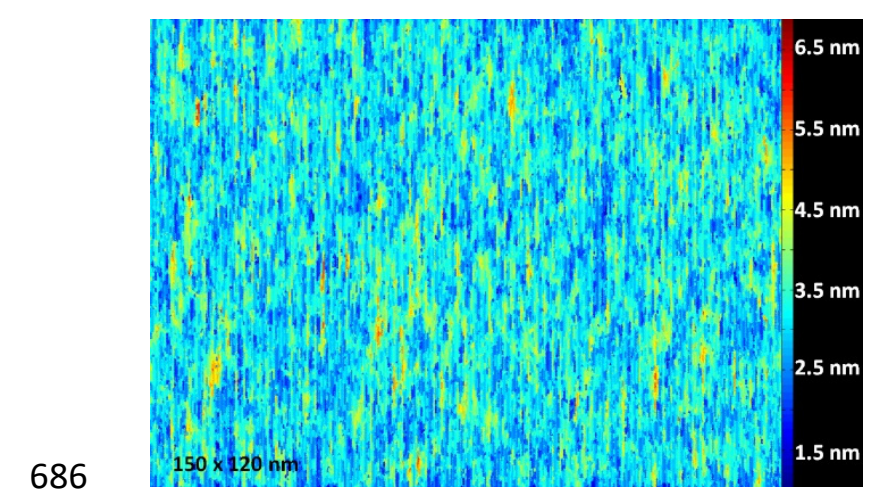

